\title{
VEGFR2-targeted transfection of melanoma tumors via \\ ultrasound mediated destruction of plasmid-bearing
}

\author{
microbubbles
}

\author{
A Dissertation Presented to the Faculty of the \\ School of Engineering and Applied Science \\ University of Virginia \\ In Partial Fulfillment \\ of the Requirements for the Degree \\ Doctor of Philosophy in Biomedical Engineering
}

By

Yuhling Wang

April 2014 
APPROVAL SHEET

The dissertation

is submitted in partial fulfillment of the requirements

for the degree of

Doctor of Philosophy

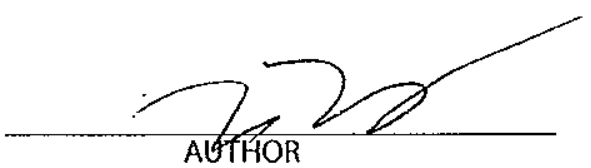

The dissertation has been read and approved by the examining committee:

Michael B. Lawrence, Ph.D.

Advisor

John A. Hossack, Ph.D.

Shayn Peirce-Cottler, Ph.D.

Alexander L. Klibanov, Ph.D.

Amy H. Bouton, Ph.D.

Accepted for the School of Engineering and Applied Science:

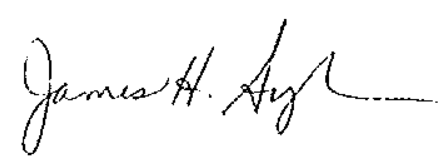

Dean, School of Engineering and Applied Science

May

2014 


\section{Abstract}

Survival rates for late stage melanoma can be as low as $7 \%$ and despite improvements in cancer therapy, surgery remains the primary treatment for melanoma. In this study we examined microbubblemediated gene delivery to B16-F1 mouse melanoma tumors as an alternative therapeutic strategy. To determine an appropriate target for tumor-specific gene delivery, targeted-microbubble imaging was used to compare the expression patterns of the angiogenesis marker VEGFR2 and the inflammation marker VCAM-1 in B16 melanomas since angiogenesis and inflammation are both associated with tumor progression. Results showed that bubbles targeted to VEGFR2 bound specifically to the tumor endothelium and not to non-tumor tissue endothelium. However, VCAM-1-targeted bubble binding was elevated in both tumor and non-tumor tissue. Since VCAM-1 is not constitutively expressed on endothelial cells, this suggests systemic inflammation in tumor-bearing mice. This will be explored in future work since systemic inflammation can have negative implications for tumor immunotherapies.

Next, VEGFR2-targeted microbubbles were used to deliver RFP reporter plasmid as a proof of concept for gene delivery to melanoma tumors. Plasmids were attached to cationic bubbles via charge coupling. Sonoporation was induced via a $1 \mathrm{MHz}$ transducer set at $0.37 \mathrm{~W} / \mathrm{cm}^{2}$ in intensity and $100 \%$ duty cycle. Immunohistochemical staining of RFP expression in tumor and muscle tissue showed tumor specific transfection. Transfection mostly occurred near blood vessels, demonstrating that microbubblemediated delivery of therapeutic genes would be most useful for highly perfused tumors. Future work would include increasing the DNA payload and bubble transfection efficiency using the cationic polymer PEI to possibly transfect cells further away from the vessel wall. 
Table of contents

Abstract

List of figures $\quad \mathrm{iii}$

List of abbreviations $\quad$ iv

Chapter 1: Introduction $\quad 1$

Aims and outline of the study 6

$\begin{array}{ll}\text { References } & 7\end{array}$

Chapter 2: Microbubble imaging of VEGFR2 and VCAM-1 expression in B16-F1 melanoma tumors 12

$\begin{array}{ll}\text { Introduction } & 12\end{array}$

Methods and materials $\quad 13$

$\begin{array}{lr}\text { Results } & 22\end{array}$

$\begin{array}{ll}\text { Discussion } & 32\end{array}$

$\begin{array}{ll}\text { References } & 34\end{array}$

Chapter 3: Targeted transfection of B16-F1 melanoma tumors using a RFP reporter gene 37

$\begin{array}{ll}\text { Introduction } & 37\end{array}$

$\begin{array}{ll}\text { Methods and materials } & 38\end{array}$

$\begin{array}{ll}\text { Results } & 47\end{array}$

$\begin{array}{ll}\text { Discussion } & 51\end{array}$

$\begin{array}{ll}\text { References } & 54\end{array}$

Chapter 4: Future work 
Figure 1-1 Microbubble and ultrasound-mediated gene delivery to B16-F1 melanoma tumors

Figure 2-1 Preparation of targeted microbubbles 14

Figure 2-2 Parallel plate flow chamber 17

Figure 2-3 Transducer placement 18

Figure 2-4 Examples of ROI's drawn from the B mode image 20

Figure 2-5 Example of ROI's obtained from thresholding of grayscale image 22

Figure 2-6 Optimization of antibody to bubble conjugation ratio 23

Figure 2-7 Example size distribution of targeted bubbles 24

Figure 2-8 Microbubble flow chamber binding assay 25

Figure 2-9 Example ultrasound image of control or targeted-bubble binding in B16-F1 26

mouse melanoma model

Figure 2-10 Example plot of time vs. average intensity obtained from the ultrasound 27 images shown in Figure 2-9

Figure 2-11 Comparison of average signal intensity of VEGFR2-targeted and control 28 bubbles after 10 min washout in different tissues

Figure 2-12 Comparison of average signal intensity of VCAM-1-targeted and control 29 bubbles after 10 min washout in different tissues

Figure 2-13 CD31 and VEGFR2 double stain in tumor, adjacent non-tumor area, and 31 contralateral leg muscle

Figure 2-14 Comparison of vessel density between tumor, adjacent non-tumor tissue, 32 and contralateral leg muscle

Figure 2-15 Comparison of VEGFR2 ${ }^{+}$endothelium in tumor, adjacent non-tumor tissue, 32 and contralateral leg muscle

Figure 3-1 Experimental setup for transducer intensity measurement 39

Figure 3-2 Transducer placement for in vitro sonoporation experiment 41

Figure 3-3 Figure 3-3: Method for measuring RFP ${ }^{+}$area within $10 \mu \mathrm{m}$ of blood vessels 46

Figure 3-4 Ultrasound intensity measurement 47

Figure 3-5 GFP transfection of HEK-293 cells in OptiCell chambers using sonoporation 48

Figure 3-6 Measurement of the DNA payload of cationic microbubbles 49

Figure 3-7 Non-perfused area (blue arrow) observed in the tumor after repeated 50

Figure 3-8 Immunohistochemical staining for CD31 (blue) and RFP (brownish red) in 51 transfected tissue

Figure 3-9 Percentage of RFP ${ }^{+}$area within different distances of tumor blood vessels 51 


\section{List of abbreviations}

\begin{tabular}{|c|c|}
\hline A647 & Alexa Fluor 647 \\
\hline $\mathrm{Ab}$ & Antibody \\
\hline Ave. & Average \\
\hline BLI & Bioluminescence imaging \\
\hline BRAF & V-raf murine sarcoma viral oncogene homolog B1 \\
\hline BSA & Bovine serum albumin \\
\hline $\mathrm{cm}$ & Centimeter \\
\hline CPS & Cadence contrast pulse sequence \\
\hline CT & X-ray computed tomography \\
\hline CTLA-4 & Cytotoxic T-lymphocyte antigen 4 \\
\hline d & Diameter \\
\hline DAPI & 4',6-diamidino-2-phenylindole \\
\hline$d B$ & Decibel \\
\hline DMEM & Dulbecco's modified eagle medium \\
\hline DNA & Deoxyribonucleic acid \\
\hline DPBS & Dulbecco's phosphate buffered saline \\
\hline DTAP & 1,2-distearoyl-3-trimethylammoniumpropane \\
\hline EDTA & Ethylenediaminetetraacetic acid \\
\hline FBS & Fetal bovine serum \\
\hline FDA & US food and drug administration \\
\hline FITC & Fluorescein isothiocyanate \\
\hline FMT & Fluorescence mediated tomography \\
\hline FRI & Fluorescence reflectance imaging \\
\hline G & Gauge \\
\hline GFP & Green fluorescent protein \\
\hline GMCSF & Granulocyte-macrophage colony-stimulating factor \\
\hline HEK-293 & Human embryonic kidney 293 \\
\hline HEPES & $\mathrm{N}$-2-hydroxyethylpiperazine-N-2-ethane sulfonic acid \\
\hline HIF-1 & Hypoxia-inducible factor-1 \\
\hline $\mathrm{hr}$ & Hour \\
\hline I.D. & Inner diameter \\
\hline I.V. & Intravenous \\
\hline ICAM-1 & Intercellular adhesion molecule-1 \\
\hline IFN- $\alpha$ & Interferon- $\alpha$ \\
\hline $\operatorname{lgG}$ & Immunoglobulin G \\
\hline IL-10 & Interleukin-10 \\
\hline IL-21 & Interleukin-21 \\
\hline \multicolumn{2}{|l|}{ MAdCAM- } \\
\hline 1 & Mucosal addressin cell adhesion molecule- 1 \\
\hline $\mathrm{MB}$ & Microbubble \\
\hline MDSC & Myeloid derived suppressor cell \\
\hline $\mathrm{MHz}$ & MegaHertz \\
\hline $\mathrm{Ml}$ & Mechanical index \\
\hline
\end{tabular}




\section{List of abbreviations}

\begin{tabular}{ll} 
min & Minute \\
mL & Milliliter \\
mM & Millimolar \\
MRI & Magnetic resonance imaging \\
nm & Nanometer \\
PD-1 & Programmed cell death-1 \\
PEG & Polyethylene glycol \\
PEI & Polyethylenimine \\
PET & Positron emission tomography \\
RFP & Red fluorescent protein \\
rm & Recombinant mouse \\
ROI & Region of interest \\
rpm & rotations per minute \\
RT & Room temperature \\
S.C. & Subcutaneous \\
sec & Second \\
SPECT & Single photon emission tomography \\
TGF- $\beta$ & Transforming growth factor- $\beta$ \\
TNF & Tumor necrosis factor \\
Treg & Regulatory T cell \\
Tris & Tris(hydroxymethyl)aminomethane \\
U & Units \\
$\mu$ g & Microgram \\
$\mu L$ & Microliter \\
$\mu$ m & Micrometer \\
US & Ultrasound \\
VCAM-1 & Vascular cell adhesion molecule-1 \\
VEGF & Vascular endothelial growth factor \\
VEGFR2 & Vascular endothelial growth factor receptor 2 \\
VLA-4 & Very late antigen-4 \\
W & Watt \\
& \\
\hline
\end{tabular}




\section{Chapter 1: Introduction}

\section{Melanoma}

Surgical resection is the primary treatment for melanoma (Johnson 2013), and at its early stages, melanoma is easily treatable with a survival rate of up to $95 \%$. With late stage metastatic melanoma however, the efficacy of treatment is more limited and survival rates can be as low as 7-19\% (Balch et al. 2009). Surgery is often not an option and other therapies must be used. Non-surgical treatments for melanoma include immunotherapy, chemotherapy using dacarbazine, and the inhibition of V-raf murine sarcoma viral oncogene homolog B1 (BRAF), an oncogene that is constitutively active in as many as $80 \%$ of melanoma tumor cells and activates growth signaling pathways (Flaherty 2012, Lee et al. 2013,Finn et al. 2012).

There are several FDA-approved immunotherapies for melanoma. Interferon- $\alpha$ (IFN- $\alpha$ ) or interleukin-2 (IL-2) can be injected intravenously to stimulate an immune response against tumor cells. The antibody ipilimumab blocks binding to cytotoxic T-lymphocyte antigen 4 (CTLA-4) and the resulting down-regulation of cytotoxic activity in T cells (Lee et al. 2013). Similarly, immunotherapies currently in development involve either the administering of cytokines to stimulate an immune response or the blocking of inhibitory signaling pathways in cytotoxic T cells. Cytokines that are being tested include interleukin-21 (IL-21), granulocyte-macrophage colony-stimulating factor (GMCSF), and tumor necrosis factor- $\alpha$ (TNF- $\alpha$ ). The inhibition of programmed cell death 1 (PD-1) and the activation of CD137 or CD40 are being tested to increase cytotoxic T cell activity. Other immunotherapies that are currently in clinical trials include the adoptive transfer of ex-vivo activated and expanded T cells and melanoma vaccines (Sivendran et al. 2010,Lizee et al. 2013).

Evidence of the immunogenicity of melanoma tumors suggests that immunotherapy is a promising treatment (Grotz et al. 2013,McGovern 1975). However, immunosuppression in the tumor microenvironment remains a major roadblock. Regulatory T cells (Treg) and myeloid derived suppressor 


\section{Chapter 1: Introduction}

cells (MDSC) (Meyer et al. 2011) have been found in melanoma tumors. Tumor cells have also been found to secrete immunosuppressive cytokines such as transforming growth factor $\beta$ (TGF- $\beta$ ) and interleukin 10 (IL-10) (Quezada et al. 2006). The presence of pro-inflammatory cell infiltrates in the tumor microenvironment correlates with patient survival (Jacobs et al. 2012,Erdag et al. 2012). Since the tumor microenvironment plays an important role in immunotherapy, targeted gene therapy that can guide the microenvironment towards an anti-tumor, inflammatory state would have many advantages over a treatment that stimulates general inflammation in the body.

\section{Endothelial biomarkers for melanoma-targeted gene delivery}

One explanation for the development of resistance to therapy is that tumor cells develop mutations at a higher rate than normal, and tumor cells that mutate to resist therapy are selected for during treatment (Boehm et al. 1997). Tumor endothelial cells, on the other hand, are more genetically stable and thus may be a better target for gene delivery.

Angiogenesis is a hallmark of many solid tumors (Chung et al. 2010) since hypoxia becomes a limiting factor before tumors are able to grow over 1-2 mm (Chung et al. 2010). Because of this, angiogenesis markers have been proposed as candidates for identifying the tumor endothelium. One example is the tyrosine kinase receptor vascular endothelial growth factor receptor 2 (VEGFR2).

VEGFR2 expression is low on quiescent endothelial cells and increases when hypoxic conditions trigger the activation of the transcription factor hypoxia-inducible factor-1 (HIF-1). VEGFR2 has several ligands including vascular endothelial growth factor-A (VEGF-A), VEGF-C, VEGF-D, and VEGF-E. Of the four ligands, VEGF-A plays a primary role in tumor angiogenesis. Binding of VEGF-A to VEGFR2 activates signaling pathways that result in endothelial cell survival, mitogenesis, and chemotaxis (Otrock et al. 2007). Similar to VEGFR2, the production of VEGF-A is stimulated by hypoxia through HIF-1 activation in endothelial cells. In addition, tumor cells and tumor stromal cells can aberrantly produce high levels of 


\section{Chapter 1: Introduction}

VEGF-A (Nagy et al. 2010). VEGFR2 has been found on both tumor and endothelial cells in melanoma tumors (Pisacane and Risio 2005, Rivera et al. 2008,Smith et al. 2010,Patten et al. 2010). VEGFR2 can also be expressed on cells other than endothelial cells (neuronal cells, osteoblasts, megakaryocytes, hematopoietic stem cells (Otrock et al. 2007). Since, these cells do not normally appear in melanoma tumors, VEGFR2 still remains a good candidate marker for tumor-specific gene delivery.

Besides angiogenesis, inflammation is also closely associated with both tumorigenesis and tumor progression. Reactive oxygen species released during inflammation increase the chances of DNA mutations that can give rise to tumor cells. As a result, chronic inflammation in the colon, bladder, or liver is associated with higher risks for tumor development. Once a tumor has developed, the microenvironment often remains in an inflammatory state similar to that of wound healing. For example, tumor associated macrophages can secrete growth factors and angiogenic factors (Grivennikov et al. 2010) that have a pro-tumor effect.

A possible biomarker for tumor targeting that is related to inflammation is vascular cell adhesion molecule-1 (VCAM-1). VCAM-1 is involved in the leukocyte adhesion cascade that facilitates the extravasation of leukocytes to sites of inflammation. Endothelial cells normally do not express VCAM-1 on the cell membrane but can rapidly synthesize VCAM-1 when exposed to an inflammatory cytokine such as TNF- $\alpha$ (Wijesurendra et al. 2010). VCAM-1 can bind to very late antigen-4 (VLA-4) or integrin $\alpha_{4} \beta_{7}$, which are expressed on leukocyte cell surfaces. Binding helps in stabilizing rolling and firm adhesion of leukocytes to vessel walls before transmigration (Luster et al. 2005). Several studies have found VCAM-1 to be present in melanomas at variable levels (Anastassiou et al. 2004,Anastassiou et al. 2000,van Duinen et al. 1994,Denton et al. 1992).

\section{Tumor imaging and gene delivery}




\section{Chapter 1: Introduction}

To evaluate the specificity of tumor biomarkers in animal models, several imaging modalities can be used. These include magnetic resonance imaging (MRI), x-ray computed tomography (CT), ultrasound, positron emission tomography (PET), single photon emission tomography (SPECT), fluorescence reflectance imaging (FRI), fluorescence mediated tomography (FMT), bioluminescence imaging (BLI), and intravital microscopy. Compared to these imaging modalities, ultrasound has the advantages of being relatively inexpensive, portable, and of having good sensitivity and depth of tissue penetration (Weissleder 2002,Klibanov 2005).

Ultrasound imaging in humans is generally done in the 2-10 $\mathrm{MHz}$ range with $\mathrm{mm}$ resolution but can go up to $60 \mathrm{MHz}$ in preclinical animal model imaging (Weissleder 2002) for increased resolutions of up to $40 \mu \mathrm{m}$ with decreased tissue penetration. However, in order to evaluate tumor biomarkers using ultrasound, microbubble contrast agents that are conjugated with a targeting ligand must be used. This results in a major limitation in that microbubbles are confined to the vasculature due to their size, and the tumor biomarker must be expressed on tumor endothelial cells.

Microbubbles are gas filled bubbles with lipid, albumin, or polymer shells and are typically less than $8 \mu \mathrm{m}$ in diameter to avoid entrapment in the lungs after intravenous injection. The bubbles can be air filled, but the use of gases such as sulfur hexafluoride, perfluoropropane, and perfluorobutane that have low solubility in blood can prolong bubble circulation time. Microbubbles provide high contrast in ultrasound fields due to their high compressibility and the impedance mismatch between their gas core and the surrounding blood. The high compressibility allows bubbles to oscillate and scatter ultrasound waves. Signal from non-linear oscillations can be separated from the more linear signal from tissue backscatter, increasing bubble detection sensitivity (Schneider 2011). Since they are micron-sized, microbubbles are unable to extravasate, and molecular imaging using microbubbles is constrained to targets expressed on the endothelium. A polyethylene glycol (PEG) coating on the bubble shell can help 


\section{Chapter 1: Introduction}

mask the bubble from phagocytes and increase its half-life in the bloodstream (Hernot and Klibanov 2008).

For molecular imaging, targeting ligands such as antibodies and peptides can be attached to the bubble shell. One common strategy is to conjugate biotinylated targeting ligand to biotinylated bubbles using streptavidin. Since many targeting ligands can be purchased in biotinylated form, this conjugation strategy allows the user to easily interchange between different targeting ligands. To avoid undesired immune response due to the biotin-streptavidin conjugation strategy, covalent attachment using aminereactive groups or thiol-maleimide (Klibanov 2005) can be used instead.

Microbubbles have been used for molecular imaging in angiogenesis and inflammation. Targets for angiogenesis imaging include VEGFR2 (Willmann et al. 2008,Anderson et al. 2010,Bzyl et al. 2013,Bzyl et al. 2011,Pochon et al. 2010,Tardy et al. 2010), endoglin (Deshpande et al. 2011), and the integrin $\alpha_{v} \beta_{3}$ (Anderson et al. 2011). Targets for inflammation imaging include VCAM-1 (Kaufmann et al. 2010,Kaufmann et al. 2007), mucosal addressin cell adhesion molecule-1 (MAdCAM-1) (Tlaxca et al. 2013,Bachmann et al. 2006), P-selectin (Khanicheh et al. 2012), and intercellular adhesion molecule-1 (ICAM-1) (Xie et al. 2012).

In addition to molecular imaging, microbubbles can also be used for gene delivery. Cationic lipid can be added to the bubble shell to form a net positive charge, which enables negatively charged plasmids to attach to the bubble surface. Cationic polymers such as polyethylenimine (PEI) (Sirsi et al. 2012,Jin et al. 2013) and polylysine (Borden et al. 2007) are being explored for increasing DNA payload and transfection efficiency. In addition, plasmids can be co-injected with bubbles without conjugation.

For transfection, a high mechanical index ultrasound pulse is applied, causing bubbles to rapidly expand and contract. The rapid bubble oscillation leads to pore formation in nearby cells which allows 


\section{Chapter 1: Introduction}

them to uptake DNA (Delalande et al. 2013). Alternatively, the bubble oscillation triggers increased cellular endocytosis, leading to DNA uptake (Meijering et al. 2009).

Microbubble-mediated gene delivery has several advantages over other methods of transfection. Compared to viral gene delivery, there is no risk of mutagenesis, no limitation to plasmid size, and decreased likelihood of generating an undesirable immune response. Unlike nanoparticle gene delivery platforms, toxicity is not an issue. In addition, transfection only occurs at the site of insonation which can be limited to a small area using focused ultrasound (Hernot and Klibanov 2008) or by exploiting receptor targeted microbubble platforms as described in this study.

\section{Aims and Outline of the Study}

The aim of this study was to deliver plasmid to a mouse melanoma model using microbubbles as shown in Figure 1-1. Chapter 2 focuses on determining whether an angiogenic marker (VEGFR2) or an inflammatory marker (VCAM-1) provides better tumor-targeting specificity. In Chapter 3, an RFPencoding reporter plasmid was delivered to the tumor using targeted microbubbles. Specificity was assessed using immunohistochemistry. 


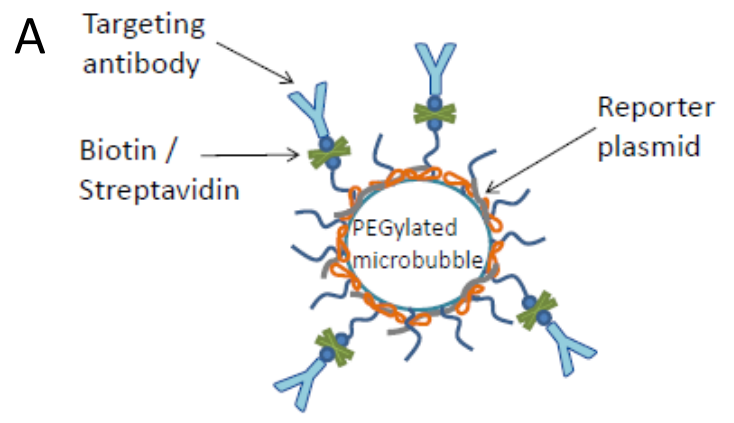

B

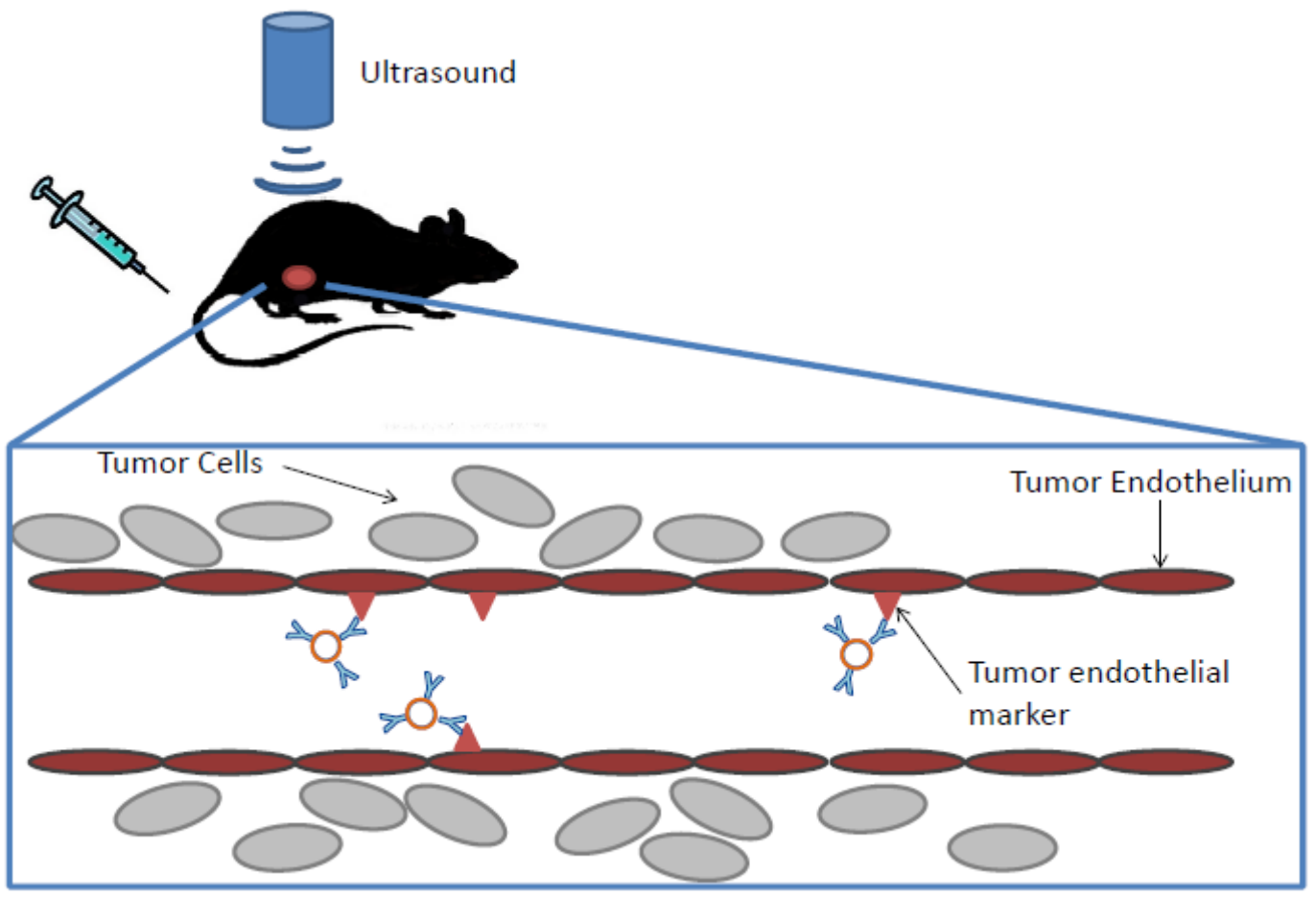

Figure 1-1: Microbubble and ultrasound-mediated gene delivery to B16-F1 melanoma tumors. A) Microbubble design B) Schematic showing plasmid-carrying microbubbles binding to the tumor endothelium after i.v. injection.

\section{References}

Anastassiou G, Esser M, Bader E, Steuhl KP, Bornfeld N. Expression of cell adhesion molecules and tumour infiltrating leucocytes in conjunctival melanoma. Melanoma Res 2004;14:381-5.

Anastassiou G, Schilling H, Stang A, Djakovic S, Heiligenhaus A, Bornfeld N. Expression of the cell adhesion molecules ICAM-1, VCAM-1 and NCAM in uveal melanoma: a clinicopathological study. Oncology 2000;58:83-8.

Anderson CR, Hu X, Zhang H, Tlaxca J, Decleves AE, Houghtaling R, Sharma K, Lawrence M, Ferrara KW, Rychak JJ. Ultrasound molecular imaging of tumor angiogenesis with an integrin targeted microbubble contrast agent. Invest Radiol 2011;46:215-24. 


\section{Chapter 1: Introduction}

Anderson CR, Rychak JJ, Backer M, Backer J, Ley K, Klibanov AL. scVEGF microbubble ultrasound contrast agents: a novel probe for ultrasound molecular imaging of tumor angiogenesis. Invest Radiol 2010;45:579-85.

Bachmann C, Klibanov AL, Olson TS, Sonnenschein JR, Rivera-Nieves J, Cominelli F, Ley KF, Lindner JR, Pizarro TT. Targeting mucosal addressin cellular adhesion molecule (MAdCAM)-1 to noninvasively image experimental Crohn's disease. Gastroenterology 2006;130:8-16.

Balch CM, Gershenwald JE, Soong SJ, Thompson JF, Atkins MB, Byrd DR, Buzaid AC, Cochran AJ, Coit DG, Ding S, Eggermont AM, Flaherty KT, Gimotty PA, Kirkwood JM, McMasters KM, Mihm MC,Jr, Morton DL, Ross MI, Sober AJ, Sondak VK. Final version of 2009 AJCC melanoma staging and classification. J Clin Oncol 2009;27:6199-206.

Boehm T, Folkman J, Browder T, O'Reilly MS. Antiangiogenic therapy of experimental cancer does not induce acquired drug resistance. Nature 1997;390:404-7.

Borden MA, Caskey CF, Little E, Gillies RJ, Ferrara KW. DNA and polylysine adsorption and multilayer construction onto cationic lipid-coated microbubbles. Langmuir 2007;23:9401-8.

Bzyl J, Lederle W, Rix A, Grouls C, Tardy I, Pochon S, Siepmann M, Penzkofer T, Schneider M, Kiessling F, Palmowski M. Molecular and functional ultrasound imaging in differently aggressive breast cancer xenografts using two novel ultrasound contrast agents (BR55 and BR38). Eur Radiol 2011;21:1988-95.

Bzyl J, Palmowski M, Rix A, Arns S, Hyvelin JM, Pochon S, Ehling J, Schrading S, Kiessling F, Lederle W. The high angiogenic activity in very early breast cancer enables reliable imaging with VEGFR2-targeted microbubbles (BR55). Eur Radiol 2013;23:468-75.

Chung AS, Lee J, Ferrara N. Targeting the tumour vasculature: insights from physiological angiogenesis. Nat Rev Cancer 2010;10:505-14.

Delalande A, Kotopoulis S, Postema M, Midoux P, Pichon C. Sonoporation: mechanistic insights and ongoing challenges for gene transfer. Gene 2013;525:191-9.

Denton KJ, Stretch JR, Gatter KC, Harris AL. A study of adhesion molecules as markers of progression in malignant melanoma. J Pathol 1992;167:187-91.

Deshpande N, Ren Y, Foygel K, Rosenberg J, Willmann JK. Tumor angiogenic marker expression levels during tumor growth: longitudinal assessment with molecularly targeted microbubbles and US imaging. Radiology 2011;258:804-11.

Erdag G, Schaefer JT, Smolkin ME, Deacon DH, Shea SM, Dengel LT, Patterson JW, Slingluff CL,Jr. Immunotype and immunohistologic characteristics of tumor-infiltrating immune cells are associated with clinical outcome in metastatic melanoma. Cancer Res 2012;72:1070-80.

Finn L, Markovic SN, Joseph RW. Therapy for metastatic melanoma: the past, present, and future. BMC Med 2012;10:23,7015-10-23. 


\section{Chapter 1: Introduction}

Flaherty KT. Targeting metastatic melanoma. Annu Rev Med 2012;63:171-83.

Grivennikov SI, Greten FR, Karin M. Immunity, inflammation, and cancer. Cell 2010;140:883-99.

Grotz TE, Vaince F, Hieken TJ. Tumor-infiltrating lymphocyte response in cutaneous melanoma in the elderly predicts clinical outcomes. Melanoma Res 2013;23:132-7.

Hernot S, Klibanov AL. Microbubbles in ultrasound-triggered drug and gene delivery. Adv Drug Deliv Rev 2008;60:1153-66.

Jacobs JF, Nierkens S, Figdor CG, de Vries IJ, Adema GJ. Regulatory T cells in melanoma: the final hurdle towards effective immunotherapy?. Lancet Oncol 2012;13:e32-42.

Jin Q, Wang Z, Yan F, Deng Z, Ni F, Wu J, Shandas R, Liu X, Zheng H. A novel cationic microbubble coated with stearic acid-modified polyethylenimine to enhance DNA loading and gene delivery by ultrasound. PLoS One 2013;8:e76544.

Johnson TM. Guidelines of care for the management of primary cutaneous melanoma. J Am Acad Dermatol 2013;69:1049-50.

Kaufmann BA, Carr CL, Belcik JT, Xie A, Yue Q, Chadderdon S, Caplan ES, Khangura J, Bullens S, Bunting S, Lindner JR. Molecular imaging of the initial inflammatory response in atherosclerosis: implications for early detection of disease. Arterioscler Thromb Vasc Biol 2010;30:54-9.

Kaufmann BA, Sanders JM, Davis C, Xie A, Aldred P, Sarembock IJ, Lindner JR. Molecular imaging of inflammation in atherosclerosis with targeted ultrasound detection of vascular cell adhesion molecule-1. Circulation 2007;116:276-84.

Khanicheh E, Mitterhuber M, Kinslechner K, Xu L, Lindner JR, Kaufmann BA. Factors affecting the endothelial retention of targeted microbubbles: influence of microbubble shell design and cell surface projection of the endothelial target molecule. J Am Soc Echocardiogr 2012;25:460-6.

Klibanov AL. Ligand-carrying gas-filled microbubbles: ultrasound contrast agents for targeted molecular imaging. Bioconjug Chem 2005;16:9-17.

Lee C, Collichio F, Ollila D, Moschos S. Historical review of melanoma treatment and outcomes. Clin Dermatol 2013;31:141-7.

Lizee G, Overwijk WW, Radvanyi L, Gao J, Sharma P, Hwu P. Harnessing the power of the immune system to target cancer. Annu Rev Med 2013;64:71-90.

Luster AD, Alon R, von Andrian UH. Immune cell migration in inflammation: present and future therapeutic targets. Nat Immunol 2005;6:1182-90.

McGovern VJ. Spontaneous regression of melanoma. Pathology 1975;7:91-9. 


\section{Chapter 1: Introduction}

Meijering BD, Juffermans $L$, van Wamel A, Henning RH, Zuhorn IS, Emmer M, Versteilen AM, Paulus WJ, van Gilst WH, Kooiman K, de Jong N, Musters RJ, Deelman LE, Kamp O. Ultrasound and microbubbletargeted delivery of macromolecules is regulated by induction of endocytosis and pore formation. Circ Res 2009;104:679-87.

Meyer C, Sevko A, Ramacher M, Bazhin AV, Falk CS, Osen W, Borrello I, Kato M, Schadendorf D, Baniyash $\mathrm{M}$, Umansky V. Chronic inflammation promotes myeloid-derived suppressor cell activation blocking antitumor immunity in transgenic mouse melanoma model. Proc Natl Acad Sci U S A 2011;108:17111-6.

Nagy JA, Chang SH, Shih SC, Dvorak AM, Dvorak HF. Heterogeneity of the tumor vasculature. Semin Thromb Hemost 2010;36:321-31.

Otrock ZK, Makarem JA, Shamseddine Al. Vascular endothelial growth factor family of ligands and receptors: review. Blood Cells Mol Dis 2007;38:258-68.

Patten SG, Adamcic U, Lacombe K, Minhas K, Skowronski K, Coomber BL. VEGFR2 heterogeneity and response to anti-angiogenic low dose metronomic cyclophosphamide treatment. BMC Cancer 2010;10:683.

Pisacane AM, Risio M. VEGF and VEGFR-2 immunohistochemistry in human melanocytic naevi and cutaneous melanomas. Melanoma Res 2005;15:39-43.

Pochon S, Tardy I, Bussat P, Bettinger T, Brochot J, von Wronski M, Passantino L, Schneider M. BR55: a lipopeptide-based VEGFR2-targeted ultrasound contrast agent for molecular imaging of angiogenesis. Invest Radiol 2010;45:89-95.

Quezada SA, Peggs KS, Curran MA, Allison JP. CTLA4 blockade and GM-CSF combination immunotherapy alters the intratumor balance of effector and regulatory T cells. J Clin Invest 2006;116:1935-45.

Rivera RS, Nagatsuka H, Siar CH, Gunduz M, Tsujigiwa H, Han PP, Katase N, Tamamura R, Ng KH, Naomoto Y, Nakajima M, Nagai N. Heparanase and vascular endothelial growth factor expression in the progression of oral mucosal melanoma. Oncol Rep 2008;19:657-61.

Schneider M. Ultrasound Contrast Agents. In: Kiessling F, Pichler BJ, eds.: Springer Berlin Heidelberg, 2011:219-29.

Sirsi SR, Hernandez SL, Zielinski L, Blomback H, Koubaa A, Synder M, Homma S, Kandel JJ, Yamashiro DJ, Borden MA. Polyplex-microbubble hybrids for ultrasound-guided plasmid DNA delivery to solid tumors. J Control Release 2012;157:224-34.

Sivendran S, Glodny B, Pan M, Merad M, Saenger Y. Melanoma immunotherapy. Mt Sinai J Med 2010;77:620-42.

Smith NR, Baker D, James NH, Ratcliffe K, Jenkins M, Ashton SE, Sproat G, Swann R, Gray N, Ryan A, Jurgensmeier JM, Womack C. Vascular endothelial growth factor receptors VEGFR-2 and VEGFR-3 are localized primarily to the vasculature in human primary solid cancers. Clin Cancer Res 2010;16:3548-61. 
Tardy I, Pochon S, Theraulaz M, Emmel P, Passantino L, Tranquart F, Schneider M. Ultrasound molecular imaging of VEGFR2 in a rat prostate tumor model using BR55. Invest Radiol 2010;45:573-8.

Tlaxca JL, Rychak JJ, Ernst PB, Konkalmatt PR, Shevchenko TI, Pizzaro TT, Rivera-Nieves J, Klibanov AL, Lawrence MB. Ultrasound-based molecular imaging and specific gene delivery to mesenteric vasculature by endothelial adhesion molecule targeted microbubbles in a mouse model of Crohn's disease. J Control Release 2013;165:216-25.

van Duinen CM, van den Broek LJ, Vermeer BJ, Fleuren GJ, Bruijn JA. The distribution of cellular adhesion molecules in pigmented skin lesions. Cancer 1994;73:2131-9.

Weissleder R. Scaling down imaging: molecular mapping of cancer in mice. Nat Rev Cancer 2002;2:11-8.

Wijesurendra RS, Jefferson A, Choudhury RP. Target: ligand interactions of the vascular endothelium. Implications for molecular imaging in inflammation. Integr Biol (Camb) 2010;2:467-82.

Willmann JK, Lutz AM, Paulmurugan R, Patel MR, Chu P, Rosenberg J, Gambhir SS. Dual-targeted contrast agent for US assessment of tumor angiogenesis in vivo. Radiology 2008;248:936-44.

Xie A, Belcik T, Qi Y, Morgan TK, Champaneri SA, Taylor S, Davidson BP, Zhao Y, Klibanov AL, Kuliszewski MA, Leong-Poi $H$, Ammi A, Lindner JR. Ultrasound-mediated vascular gene transfection by cavitation of endothelial-targeted cationic microbubbles. JACC Cardiovasc Imaging 2012;5:1253-62. 


\section{Introduction}

In this chapter, we will compare the tumor-targeting specificity of VEGFR2- and VCAM-1targeted microbubbles in B16-F1 mouse melanoma tumors. VEGFR2 is a marker of angiogenesis that is expressed on the endothelial cells of many tumors. Microbubbles have been shown to successfully target tumor vasculature in vivo using several different targeting ligands that bind to VEGFR2. Antibody targeting ligands include a monoclonal rat anti-mouse VEGFR2 antibody (Clone Avas12a1) from eBioscience (Rychak et al. 2007, Willmann et al. 2008, Deshpande et al. 2011,Warram et al. 2011) and a polyclonal goat anti-mouse VEGFR2 antibody from R\&D Systems (Palmowski et al. 2008). Non-antibody ligands include a single-chain VEGF construct (Anderson et al. 2010) and the heterodimer peptide incorporated in Bracco's BR55 bubbles (Bzyl et al. 2013,Bzyl et al. 2011,Pochon et al. 2010). Targeting ligands that recognize other angiogenesis markers such as endoglin and integrin $\alpha_{v} \beta_{3}$ (Willmann et al. 2008,Deshpande et al. 2011,Warram et al. 2011) have been conjugated onto the microbubble surface have distinct binding patterns, suggesting that VEGFR2 expression did not perfectly track other angiogenesis markers in the tumor. In addition, VEGFR2 imaging with targeted microbubbles was able to distinguish between tumors that were more angiogenic and tumors that were less angiogenic (Palmowski et al. 2008,Bzyl et al. 2011,Tardy et al. 2010).

VCAM-1 has been shown to be an effective target for microbubble-mediated molecular imaging of inflammation. Several different targeting ligands have been used in VCAM-1 imaging, including two monoclonal rat anti-mouse VCAM-1 antibodies (clone MK2.7 (Kaufmann et al. 2007,Kaufmann et al. 2010b,Kaufmann et al. 2010a,Behm et al. 2008), clone 429 (Wu et al. 2011)) and a nanobody that binds to both human and murine VCAM-1 (cAbVCAM1-5) (Hernot et al. 2012). VCAM-1-targeted microbubble imaging has been successfully applied to cardiovascular disease including atherosclerosis (Kaufmann et al. 2007,Kaufmann et al. 2010a,Wu et al. 2011) and ischemic injury (Kaufmann et al. 2010b,Behm et al. 
2008). In addition, VCAM-1-targeted microbubble binding was shown to be higher than control microbubble binding in a mouse model of colon adenocarcinoma (Hernot et al. 2012).

Rat monoclonal antibodies were used as the targeting ligand in our study since they are readily available in a biotinylated format from commercial manufacturers. The rat monoclonal antibodies can be substituted with humanized antibodies (Carter 2006) or peptides (Weissleder et al. 2005,Anderson et al. 2010) in future work to decrease immunogenicity.

\section{Methods and Materials:}

\section{Preparation of targeted microbubbles}

The biotinylated microbubbles used for this study were lipid-shelled with a perfluorocarbon gas core. To prepare targeted microbubbles, biotin-streptavidin linkage was used to attach biotinylated antiVEGFR2 antibody (Clone Avas12a1, eBioscience, San Diego, CA) or biotinylated anti-VCAM-1 antibody (Clone 429, eBioscience, San Diego, CA) to the bubble shell. Degassed saline was used during all washing steps to decrease gas loss from the bubbles. To prepare degassed saline, $0.9 \%$ sodium chloride solution (Baxter Healthcare, Deerfield, IL) was placed in a bath sonicator under vacuum. After 15 min, the saline was then transferred to a syringe with perfluorocarbon gas saturating the headspace and shaken to displace any remaining atmospheric gas.

The antibody conjugation process is summarized in Figure 2-1. First, biotinylated bubbles were washed three times to remove excess shell material in the bubble suspension. In each washing step, bubbles were diluted in degassed saline and centrifuged at 1000 rpm for 5 minutes in a swinging bucket rotor centrifuge with a radius of $20 \mathrm{~cm}$. The bubbles formed a cake at the top of the centrifuge tube while excess shell material remained in the infranatant which was then removed. Next, flotation was used to remove large bubbles $(d>7 \mu \mathrm{m})$. During flotation, bubbles were diluted in degassed saline to a 
total volume of $2 \mathrm{~mL}$ in a $3 \mathrm{~mL}$ plastic syringe (BD Medical, Franklin Lakes, NJ). Letting the solution sit for 5 minutes allowed bubbles to float to the top of the solution. Since larger bubbles reach the top quicker than smaller bubbles, size separation was achieved by keeping the bottom $1.5 \mathrm{~mL}$ of the solution while discarding the top $0.5 \mathrm{~mL}$. The size distribution and concentration of bubbles were measured using a Multisizer 3 Coulter Counter (Beckman Coulter, Miami, FL), and the flotation step was repeated as necessary to remove microbubbles larger than $7 \mu \mathrm{m}$ diameter. Streptavidin (Sigma-Aldrich, St. Louis, MO) was then added to the bubbles at 3 ug / 10 $0^{7}$ microbubbles (MB) (Lindner et al. 2001) and incubated for 7 min at room temperature followed by two washing steps to remove excess streptavidin. Biotinylated antibody was then added at the appropriate concentration and incubated for $10 \mathrm{~min}$ at room temperature followed by two washing steps to remove unbound ligand. Control bubbles conjugated with biotinylated rat IgG2a $\mathrm{k}$ isotype control antibody (eBioscience, San Diego, CA) were prepared using the same protocol.

- Biotin 4 Streptavidin Biotinylated antibody

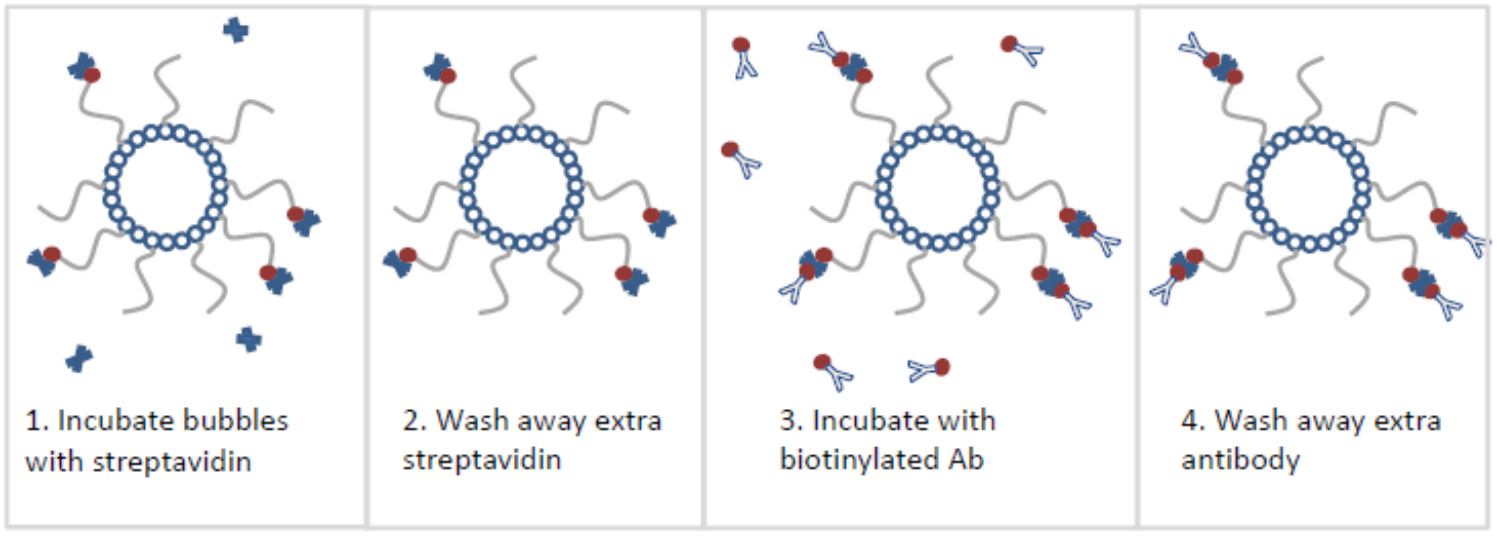

Figure 2-1: Preparation of targeted microbubbles

\section{Determination of antibody to microbubble conjugation ratio}

Flow cytometry was used to determine the antibody to microbubble ratio necessary for saturation of the streptavidin binding sites during step 3 of the targeted bubble preparation procedure 
Chapter 2: Microbubble imaging of VEGFR2 and VCAM-1 expression in B16-F1 melanoma tumors

summarized in Figure 2-1. Antibodies were first labeled using an AlexaFluor 647 monoclonal antibody labeling kit (Invitrogen, Grand Island, NY) according to the manufacturer's protocol. Next, VCAM-1targeted bubbles were prepared using different labeled antibody to bubble ratios $\left(0,0.1,1,3,4 \mu \mathrm{g} / 10^{7}\right.$ $\mathrm{MB}$ ) during the incubation step. A BD FACSCalibur flow cytometer (BD Biosciences, San Diego, CA) was used to measure bubble fluorescence intensity as an indicator of the amount of conjugated antibody, and FlowJo software (Tree Star, Ashland, OR) was used for data analysis.

\section{In vitro validation of targeted microbubble binding in a flow chamber system}

\section{Cell culture}

The SVR mouse pancreatic islet endothelial cell line, which expresses VEGFR2, was used in the in vitro assay to test VEGFR2-targeted bubble binding to VEGFR2-expressing endothelial cells under flow. Failure of the microbubbles to attach under flow conditions would suggest insufficient targeting antibody on the microbubble surface. The B16-F1 melanoma cell line, which does not express VEGFR2, was used as a negative control. Both cell lines were cultured at $37^{\circ} \mathrm{C}$ and $5 \% \mathrm{CO}_{2}$. SVR cells (ATCC, Manassas, VA) were cultured in Dulbecco's Modified Eagle Medium (DMEM) with high glucose supplemented with $1 \mathrm{mM}$ sodium pyruvate, 10\% fetal bovine serum (FBS), and 1\% penicillin/streptomycin (Invitrogen, Grand Island, NY). B16-F1 cells (gift from Dr. TN Bullock at UVA) were cultured in RPMI Medium 1640 supplemented with 15 mM N-2-hydroxyethylpiperazine-N-2ethane sulfonic acid (HEPES), 5\% FBS, and 1\% penicillin/streptomycin (Invitrogen, Grand Island, NY). 0.05\% trypsin-EDTA solution (Invitrogen, Grand Island, NY) was used to detach cells for passaging.

\section{Parallel plate flow chamber assay}

A parallel plate flow chamber (Glycotech, Rockville, MD) with a gasket size of $0.50 \mathrm{~cm}$ in flow width and 0.01 inch in thickness was used to assess targeted-microbubble binding to protein or cell 
coated surfaces under laminar flow conditions. The layout of the flow chamber is shown in Figure 2-2. Polystyrene dishes (BD Biosciences, San Diego, CA or Genesee Scientific, San Diego, CA) were coated with recombinant mouse ( $\mathrm{rm}$ ) VEGFR2 or rmVCAM-1(R\&D Systems, Minneapolis, MN) at $1 \mu \mathrm{g} / \mathrm{mL}$ in Dulbecco's phosphate buffered saline (DPBS; Invitrogen, Grand Island, NY) by a 2 hr incubation at room temperature. Dishes were then washed five times with DPBS followed by a $2 \mathrm{hr}$ incubation with $1 \%$ casein blocking solution in PBS (Thermo Scientific, Waltham, MA) at room temperature. Control dishes were coated with the casein blocking solution only. Targeted microbubbles were diluted to $5 \times 10^{6}$ $\mathrm{MB} / \mathrm{mL}$ in DPBS and introduced into the flow chamber at a wall shear stress of $1 \mathrm{dyne} / \mathrm{cm}^{2}$ using a PHD 2000 syringe pump (Harvard Apparatus, Holliston, MA) set to refill mode. To quantify adhesion, bubble binding was observed using a Leitz Orthoplan upright microscope (Leitz, Wetzlar, Germany) and videos were recorded using a VIXIA HF S2 camcorder (Canon, Melville, NY) 5 min after bubbles first entered the flow chamber. The number of bubbles bound to the surface was averaged over 8 fields of view. Statistical analysis was performed using a 2-tailed Student's T-test with unequal variance.

To examine targeted bubble binding to cell surfaces, SVR cells were grown to $90 \%$ confluence on tissue culture-treated polystyrene dishes (Corning, Tewksbury, MA) for flow chamber assays. Control dishes were prepared with B16-F1 melanoma cells grown to $90 \%$ confluence. Microbubbles were diluted to $5 \times 10^{6} \mathrm{MB} / \mathrm{mL}$ in DPBS with calcium and magnesium added (Invitrogen, Grand Island, NY) and introduced into the flow chamber at $0.5 \mathrm{dyne} / \mathrm{cm}^{2}$. 
A

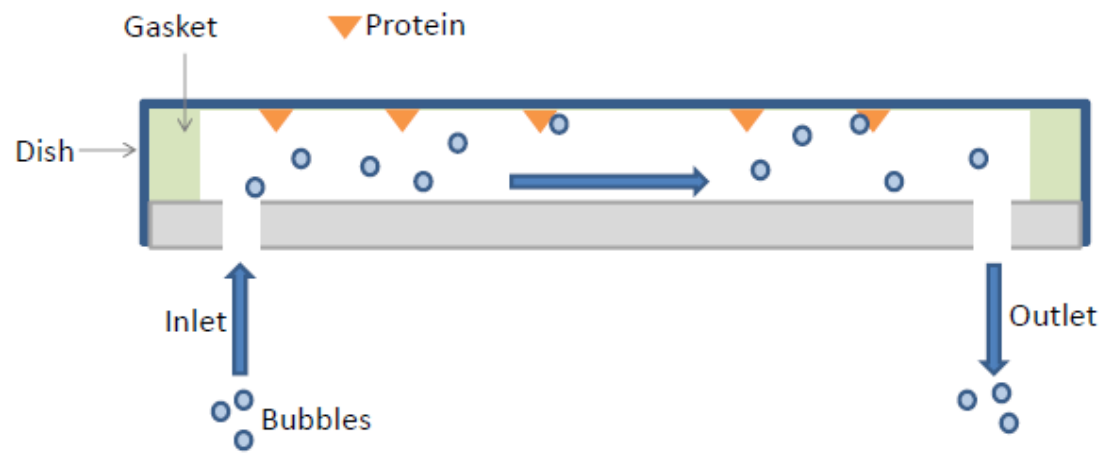

B

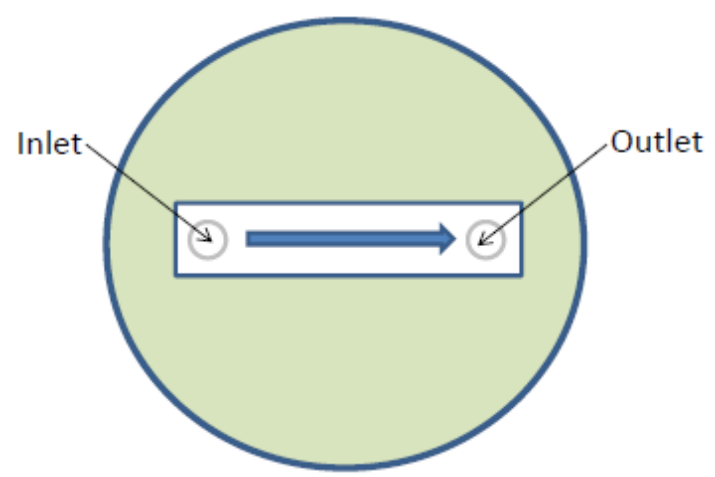

Figure 2-2: Parallel plate flow chamber. A) Cross-sectional side view of the flow chamber showing targeted bubbles flowing from left to right and binding to protein adsorbed to the dish at the top. B) Top view of the flow chamber showing the rectangular flow channel. Flow is from left to right.

\section{Induction of subcutaneous B16-F1 melanoma tumors in C57BL/6 mice}

B16-F1 melanoma cells were maintained in culture as described previously. For tumor induction, $0.5 \times 10^{6}$ cells suspended in $50 \mu \mathrm{L}$ of DPBS were injected subcutaneously into the hind limb of C57BL/6 mice using an insulin syringe with a $28 \mathrm{G}$ needle (Smiths Medical, Dublin, $\mathrm{OH}$ ). Since tumors became visible using ultrasound B mode imaging at $10 \mathrm{MHz}$ on an Acuson Sequoia 512 (Siemens, Malvern, PA) ultrasound system with a 15L8 transducer at approximately 8-9 days after injection, imaging or transfection experiments were performed on tumors beyond this time point. Tumors were visible by eye before 8 days since B16-F1 cells are dark in color, but the early tumor masses were flat and difficult to image using ultrasound.

\section{Ultrasound imaging of targeted bubble binding in B16-F1 animal model}




\section{In vivo tumor imaging}

Imaging was performed on mice with tumors that were approximately $1 \mathrm{~cm}$ in diameter. Mice were anesthetized with $2 \%$ isofluorane in air, and body temperature was kept at $37^{\circ} \mathrm{C}$ using a heating pad. Catheters constructed using $28 \mathrm{G}$ needles from insulin syringes and silastic tubing (0.3 mm I.D.; Dow Corning, Midland, MI) cut to $12 \mathrm{~cm}$ in length were inserted into the mouse tail vein for bubble injection. Catheter needles were temporarily secured in place using Mastisol liquid adhesive (Ferndale Pharma Group, Ferndale, MI). During catheter insertion, the tubing was filled with heparinized (100 $\mathrm{U} / \mathrm{mL}$ ) saline (Vycon US, Montgomeryville, PA) to prevent clot formation in the needle. $10 \times 10^{6}$ microbubbles in saline ( $50 \mu \mathrm{L}$ total volume) were injected by hand through the catheter. Bubbles were imaged at $7 \mathrm{MHz}(\mathrm{MI}=0.20)$ with a dynamic range of $50 \mathrm{~dB}$ using Cadence contrast pulse sequence (CPS) mode on an Acuson Sequoia 512 (Siemens, Malvern, PA) ultrasound system with a 15L8 transducer. The transducer was placed such that the tumor and the non-tumor bearing contralateral leg could be monitored simultaneously (Figure 2-3). Hair was removed from the mouse's legs prior to imaging using Nair lotion (Church \& Dwight, Princeton, NJ).

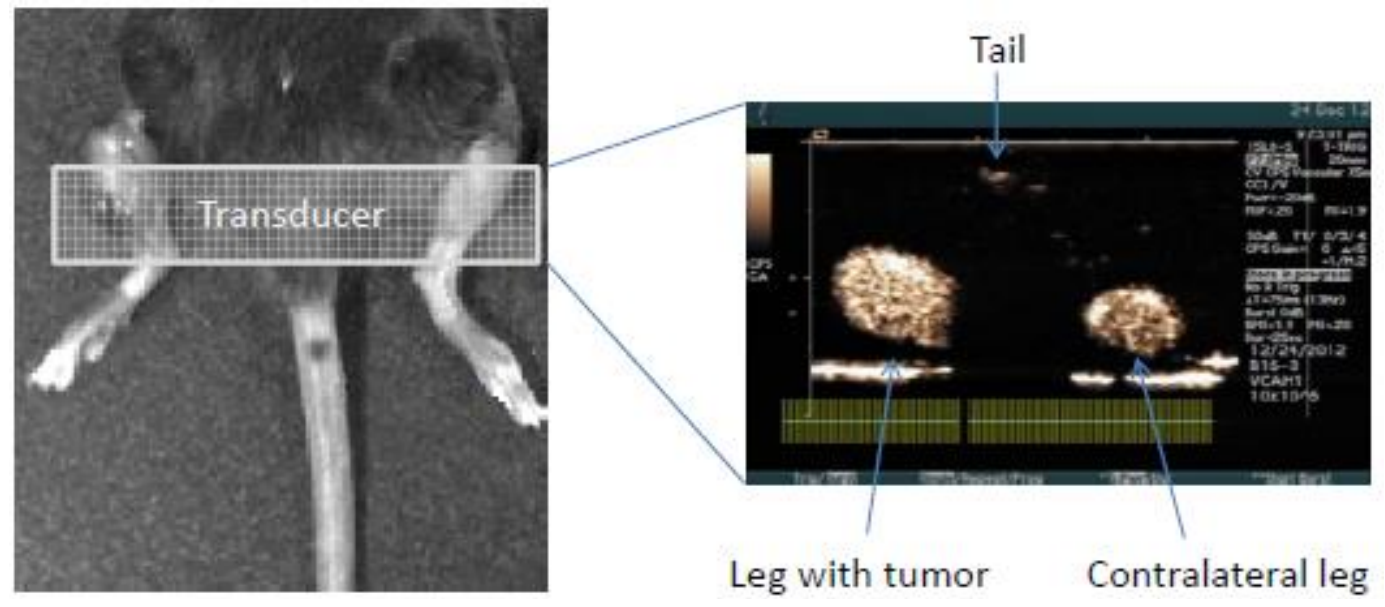

Figure 2-3: Transducer placement. The left image shows the schematic of the transducer placement as seen from the top for a mouse bearing a tumor on its left leg while the ultrasound image of the cross-section is shown in the right image. 
Chapter 2: Microbubble imaging of VEGFR2 and VCAM-1 expression in B16-F1 melanoma tumors

In order to evaluate bubble targeting specificity, a 10 min washout period was allowed for targeted bubble binding and for unbound bubbles to leave the field of view. The length of the washout period was established through observation of the time it took for isotype control bubble signal to diminish to negligible levels after initial injection. After the 10 min washout, a high power destructive pulse $(7 \mathrm{MHz}, \mathrm{MI}=1.9)$ was used to burst adhered bubbles in the field of view such that only background signal from the reperfusion of free flowing bubbles remained. The catheter was flushed with $20 \mu \mathrm{L}$ of saline after each bubble injection, and imaging of targeted bubbles and control bubbles in the same animal was separated by a 10 min interval to allow clearance of previously injected bubbles. Videos of CPS mode ultrasound imaging of the injection, washout, and destruction of bubbles were recorded using a DVD recorder connected to the ultrasound system.

\section{Quantification of targeted microbubble binding}

For data analysis, HandBrake software (handbrake.fr) was first used to transcode from DVD to mp4 format. VLC media player (VideoLAN, Paris, France) was then used to extract tiff images at 1 frame per second for analysis in ImageJ. B mode $(10 \mathrm{MHz})$ images were used to define the three regions of interest (ROI) shown in Figure 2-4: tumor, contralateral leg, and adjacent non-tumor tissue in the tumorbearing leg. The average signal intensity of each ROI was quantified at 1 second intervals using ImageJ. The student $t$ test was used to compare both the average intensity and the average intensity normalized over the peak average intensity of the three ROI's after the 10 minute washout. A total of seven animals were imaged, and a 2-tailed t test with unequal variance was used to determine statistical significance. 


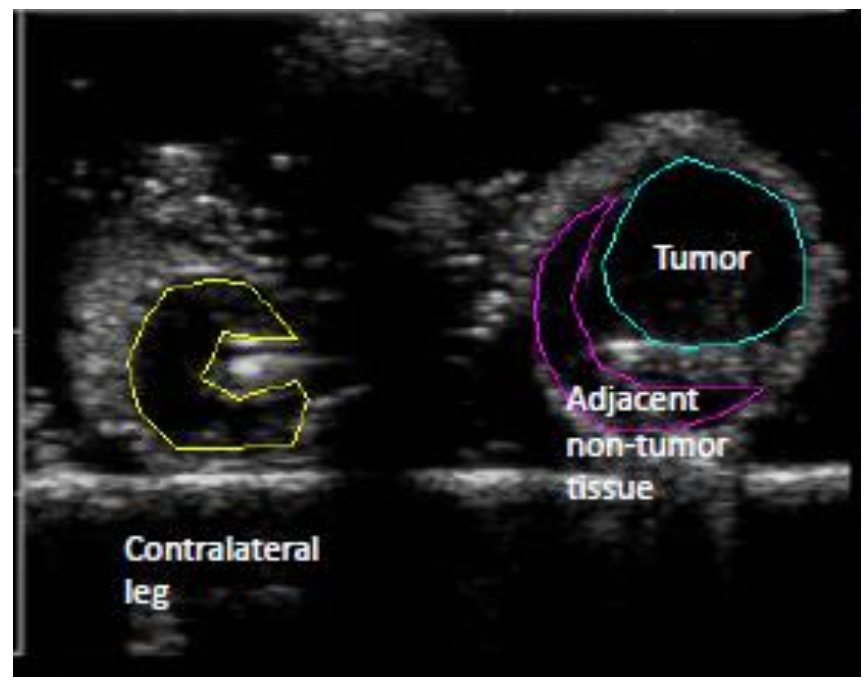

Figure 2-4: Example of ROI's drawn from the B mode image.

Verification of VEGFR2 expression on B16-F1 melanoma endothelium using immunofluorescence

\section{Antibodies used}

Since the anti-VEGFR2 antibody used for bubble targeting only stained tissues faintly during preliminary testing, we substituted the primary antibody with a polyclonal goat anti-mouse VEGFR2 antibody (R\&D Systems, Minneapolis, MN) for immunofluorescence. The secondary antibody was a Cy3labeled bovine anti-goat IgG antibody (Jackson ImmunoResearch Laboratories, West Grove, PA).

For CD31 staining, a FITC-labeled rat anti-mouse CD31 antibody (clone 390; BioLegend, San Diego, CA) was used. Staining was slightly faint, so a FITC-labeled mouse anti-rat IgG secondary antibody (eBioscience, San Diego, CA) was used to improve the signal to noise ratio.

The antibody concentrations used for staining were $0.7 \mu \mathrm{g} / \mathrm{mL}$ for both primary antibodies, 1 $\mu \mathrm{g} / \mathrm{mL}$ for the secondary antibody for CD31, and 1:200 for the secondary antibody for VEGFR2. These concentrations were determined during preliminary antibody titration experiments.

\section{Staining protocol}


Chapter 2: Microbubble imaging of VEGFR2 and VCAM-1 expression in B16-F1 melanoma tumors

Tumor-bearing mice were euthanized via ketamine overdose, and tumor, normal, and contralateral leg tissue were collected. Tissue was then embedded in Tissue-Tek O.C.T. compound (Sakura Finetek USA, Torrance, CA) and flash frozen in liquid nitrogen before sectioning at $7 \mu \mathrm{m}$ thickness using a Leica CM3050S research cryostat (Leica Microsystems GmbH, Wetzlar, Germany) set at $-22^{\circ} \mathrm{C}$. Tissue sections were adhered onto Fisherbrand Superfrost slides (Thermo Fisher Scientific, Waltham, MA) and allowed to dry overnight. Fixation was done via immersion in ice cold acetone (Avantor Performance Materials, Center Valley, PA) for $10 \mathrm{sec}$.

For staining, tissue sections were first washed 3 times for 3 minutes each with a wash buffer consisting of $0.1 \%$ Tween 20 (Sigma-Aldrich, St. Louis, MO) in DPBS. Next, tissue sections were incubated for 30 minutes at room temperature with a blocking solution consisting of $1 \%$ bovine serum albumin (BSA; American Bioanalytical, Natick, MA) in the Tween washing buffer. Sections were then washed 3 times with the washing buffer before a 45 minute incubation at room temperature with the anti-CD31 and anti-VEGFR2 primary antibodies. Afterwards, sections were washed 3 times and then incubated with the secondary antibodies for $30 \mathrm{~min}$ at RT. Unbound antibody was removed via 3 rounds of washing, and sections were mounted in VECTASHIELD mounting medium with DAPI (Vector Laboratories, Burlingame, CA).

\section{Fluorescence imaging}

Slides were imaged using an Olympus IX51 microscope with a 10x objective (Olympus America, Center Valley, PA). A Retiga-4000RV digital CCD camera (QImaging, Burnaby, BC, Canada) controlled via Q-Capture Pro 7 software (QImaging, Burnaby, BC, Canada) was used to capture grayscale images in TIFF format. The camera exposure time was set to minimize background from tissue autofluorescence and was kept constant for the same tissue types. To visualize colocalization of VEGFR2 and CD31, pseudocolor images were created from the grayscale images and overlayed in ImageJ. 


\section{Image analysis}

Vascular density was assessed by measuring the percentage of $\mathrm{CD} 31^{+}$area per FOV $(1185.15 \mathrm{x}$ $\left.888.86 \mu \mathrm{m}^{2}\right)$. The grayscale image from the FITC channel was opened in ImageJ and the thresholding function was used to draw the ROI. The lower value of the threshold was adjusted so that nonfluorescent areas were excluded from the ROI. The higher value of the threshold was adjusted to exclude any bright spots that were from staining artifacts. An example of the ROI's obtained from thresholding is shown in Figure 2-5. The threshold values were kept consistent for different images from the same slide. The area within the ROI was then calculated and divided by the total area of the FOV to get the percentage of CD31 positive area within each FOV.

VEGFR2 and CD31 co-staining was assessed by measuring the ratio of VEGFR2 ${ }^{+}$area to CD $31^{+}$ area for each FOV. The method for calculating the VEGFR2 ${ }^{+}$area was the same as that used to determine $\mathrm{CD} 31^{+}$area.

Grayscale image
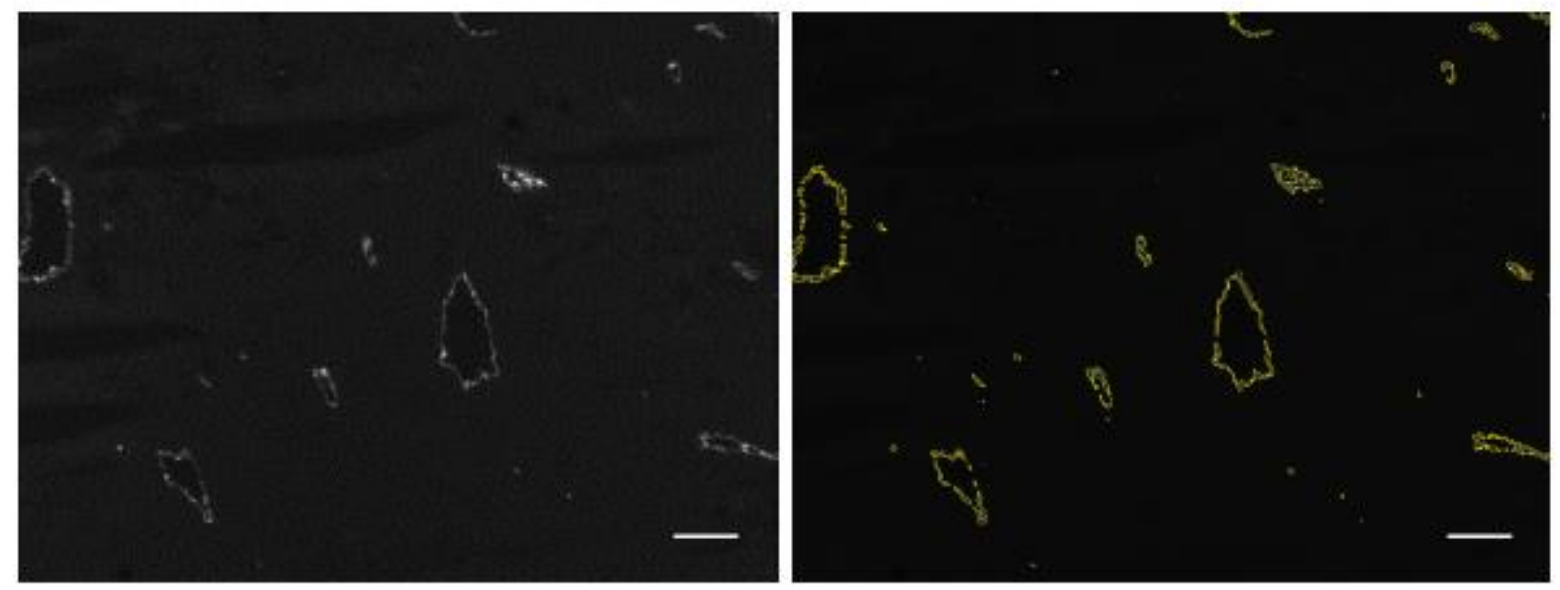

Figure 2-5: Example of ROI's obtained from thresholding of grayscale image. Scale bar: $100 \mu \mathrm{m}$.

\section{Results:}




\section{Characterization of targeted microbubbles}

Flow cytometry measurement of anti-VCAM-1 antibody conjugation to bubbles is shown in Figure 2-6. Since saturation of biotin binding sites on the bubble surface occured at an incubation concentration of $1 \mu \mathrm{g} \mathrm{Ab} / 10^{7} \mathrm{MB}$, we decided to use this concentration for preparing the targeted microbubbles used in subsequent in vitro and in vivo experiments.

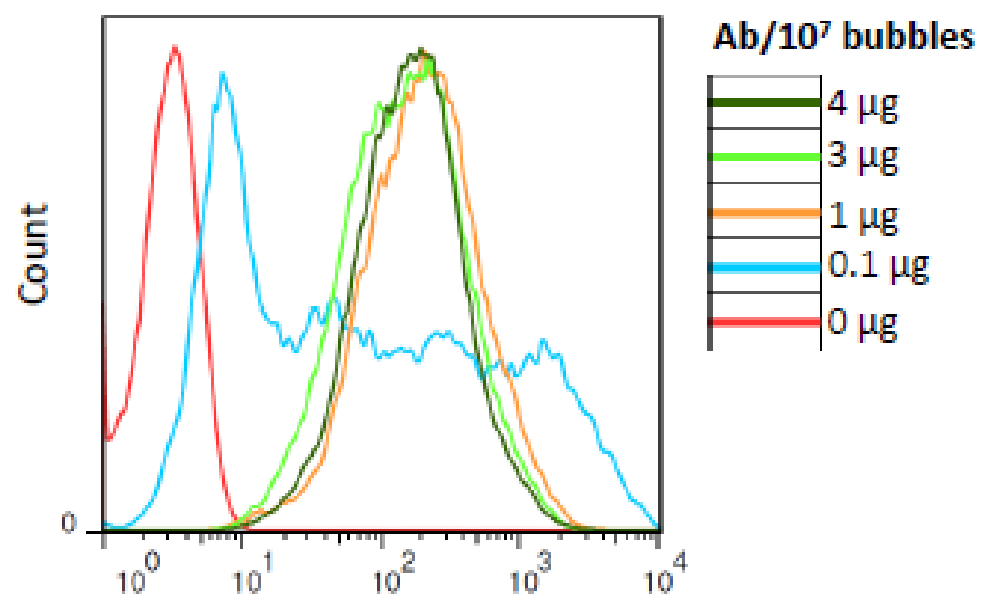

FL4H: A647 VCAM-1

Figure 2-6: Optimization of antibody to bubble conjugation ratio. Saturation occurs at $1 \mu \mathrm{g} A \mathrm{~b} / 10^{7}$ MB.

Figure 2-7 shows an example of the size distribution of the targeted bubbles measured using the Coulter Multisizer. The mean diameter was between $2-3 \mu \mathrm{m}$, and $90 \%$ of bubbles were less than $5 \mu \mathrm{m}$ in diameter. 
Chapter 2: Microbubble imaging of VEGFR2 and VCAM-1 expression in B16-F1 melanoma tumors

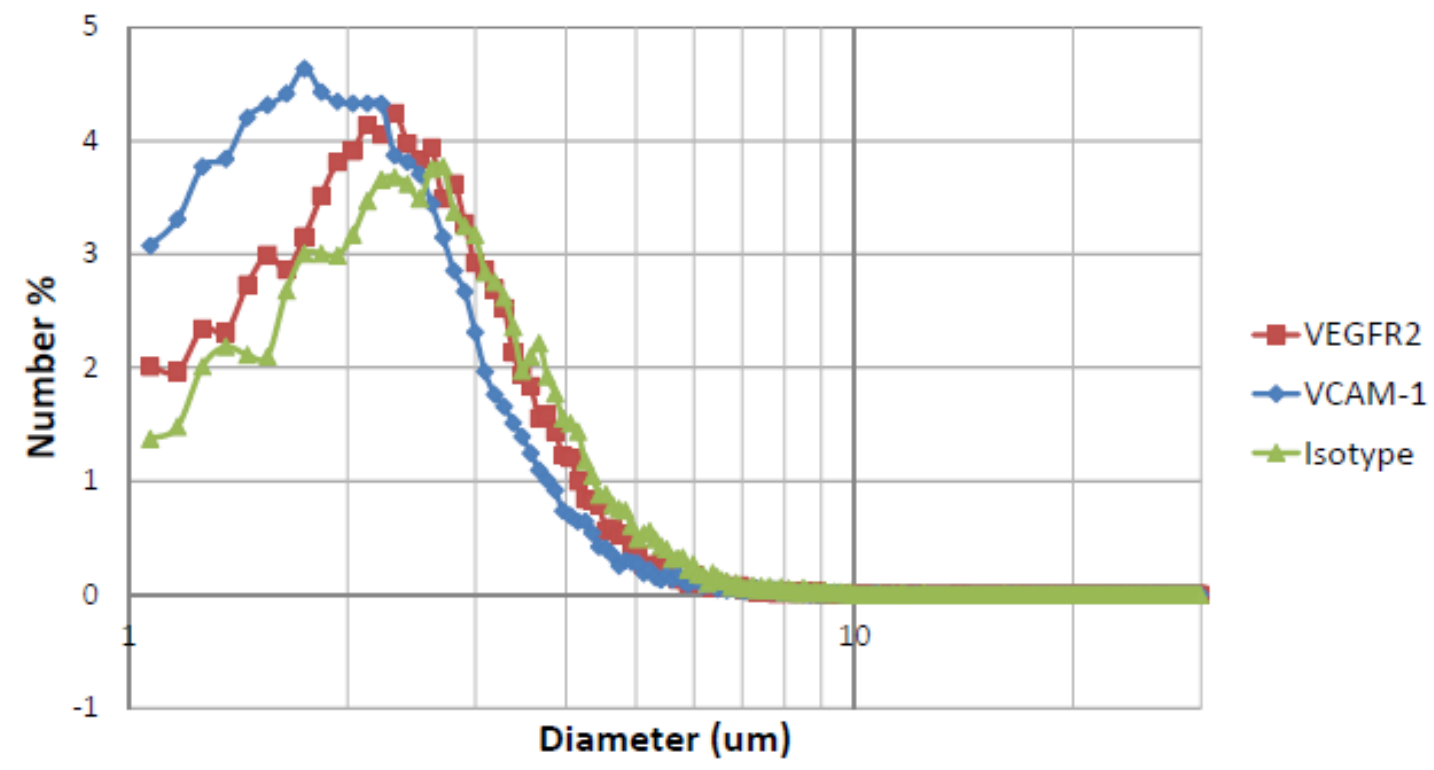

Figure 2-7: Example size distribution of targeted bubbles.

Validation of targeted microbubble binding using a parallel plate flow chamber assay

Figure 2-8 shows targeted bubble binding to protein or cell coated dishes. For the VCAM-1targeted bubbles, lowering the antibody to microbubble ratio by 10 -fold during the conjugation step led to a decrease in the number of adhered bubbles, but there was still a significant difference between targeted-bubble binding and control bubble binding. Neither VEGFR2- nor VCAM-1-targeted bubbles bound to control surfaces. 

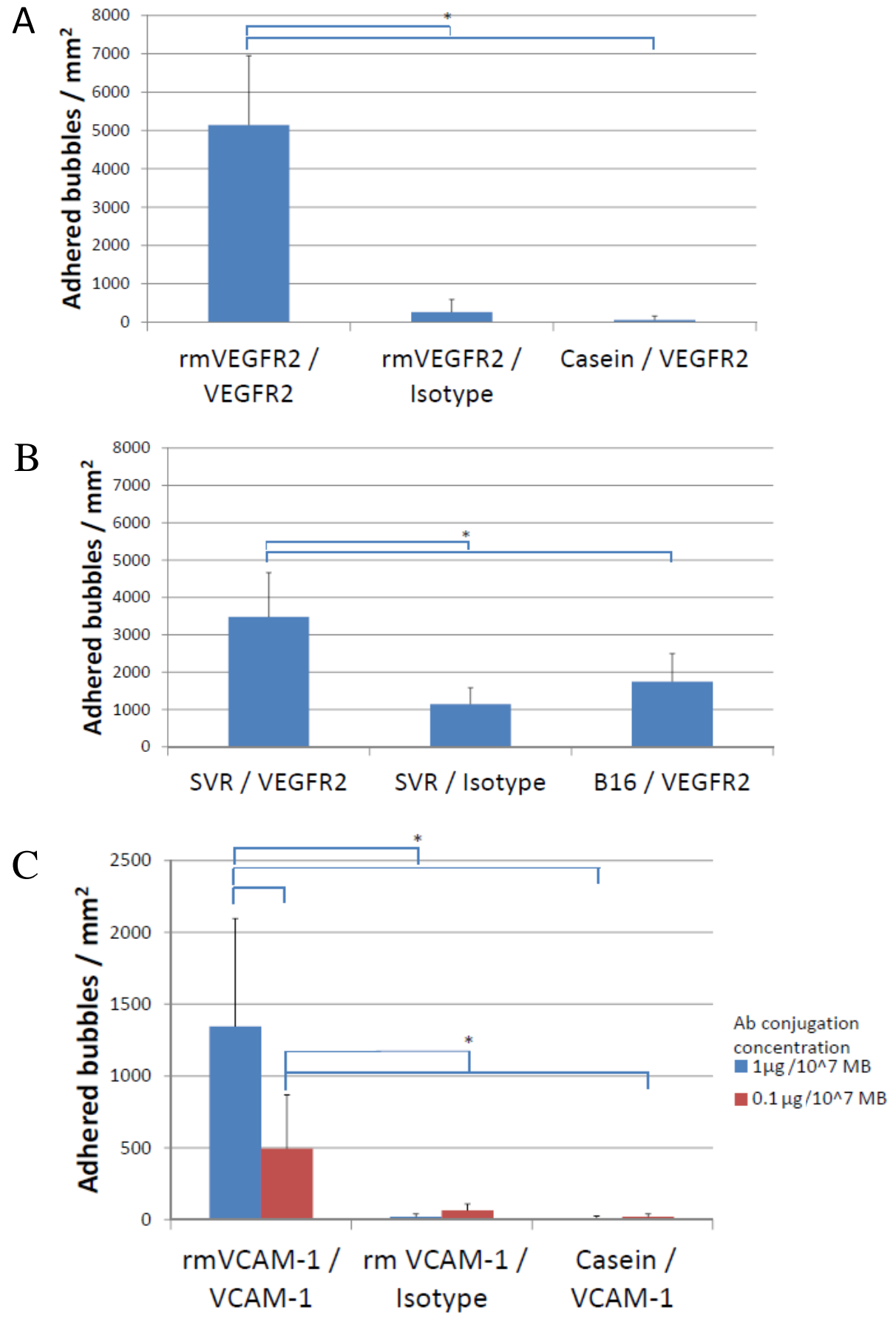

Figure 2-8: Microbubble flow chamber binding assay. A) Control or VEGFR2-targeted bubble binding to rmVEGFR2 or casein coated plates. B) Control or VEGFR2-targeted bubble binding to VEGFR2expressing SVR cells or negative control B16 cells. C) Control or VCAM-1 targeted bubble binding to rmVCAM-1 or casein coated plates. ${ }^{*} p<0.01 ; n=2$ for rmVCAM-1/Isotype and casein/VCAM-1 conditions with $0.1 \mu \mathrm{g} / 10^{7} \mathrm{MB} A \mathrm{~b}$ conjugation concentration and $\mathrm{n}=3$ for all others. Shear stress of 1 dyne $/ \mathrm{cm}^{2}$ for protein-coated surfaces and 0.5 dyne $/ \mathrm{cm}^{2}$ for cell-coated surfaces. 
Ultrasound imaging of targeted microbubble binding in B16-F1 animal model

Examples of the ultrasound images obtained at different time points during bubble perfusion in mouse tumors are shown in Figure 2-9. There were no noticeable regions of non-perfusion in the tumors. After the 10 min washout period, preferential binding of VEGFR2-targeted bubbles to the tumor vasculature could be seen in comparison to the contralateral leg. Isotype control bubbles did bind in the tumor vasculature but at lower levels compared to targeted bubbles. Bursting of the bound bubbles after the 10 min washout showed that background signal from free-flowing bubbles in circulation was low.

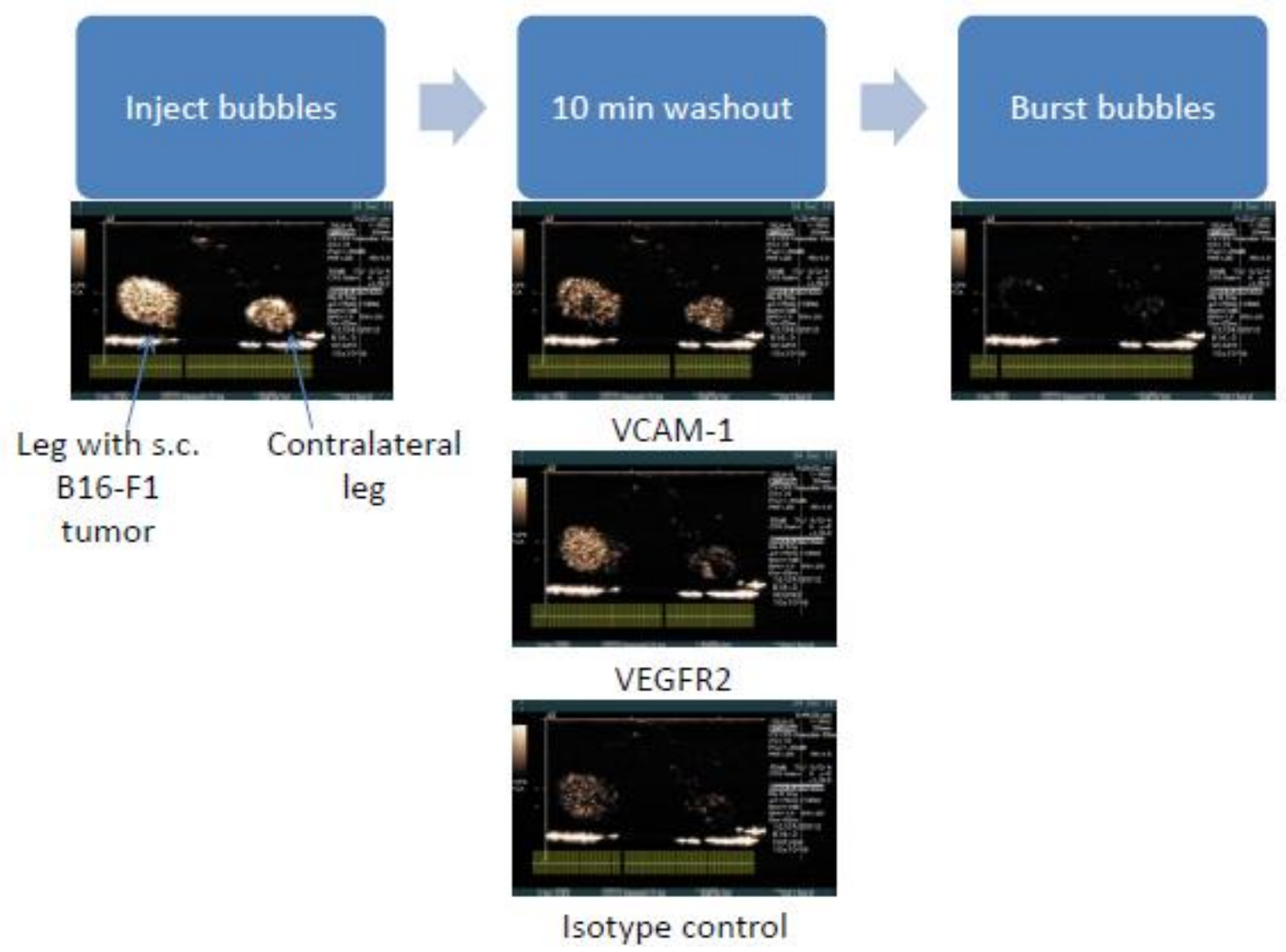

Figure 2-9: Example ultrasound images of control or targeted-bubble binding in B16-F1 mouse melanoma model. 
Average intensity values were calculated from the ultrasound images for the 3 ROI shown in

Figure 2-4. Changes in the average intensity over during VEGFR2-targeted bubble perfusion are shown in Figure 2-10 as an example. The peak average signal intensity at approximately $30 \mathrm{sec}$ after bubble injection was higher in the tumor compared to muscle tissue, indicating higher perfusion. Because of the differences in perfusion, analysis was done with both the average intensity and the average intensity normalized to the peak average intensity. Results in Figure 2-11 and Figure 2-12 show that VEGFR2targeted bubble binding was significantly higher in the tumor compared to non-tumor tissue whereas VCAM-1-targeted bubble binding was not.

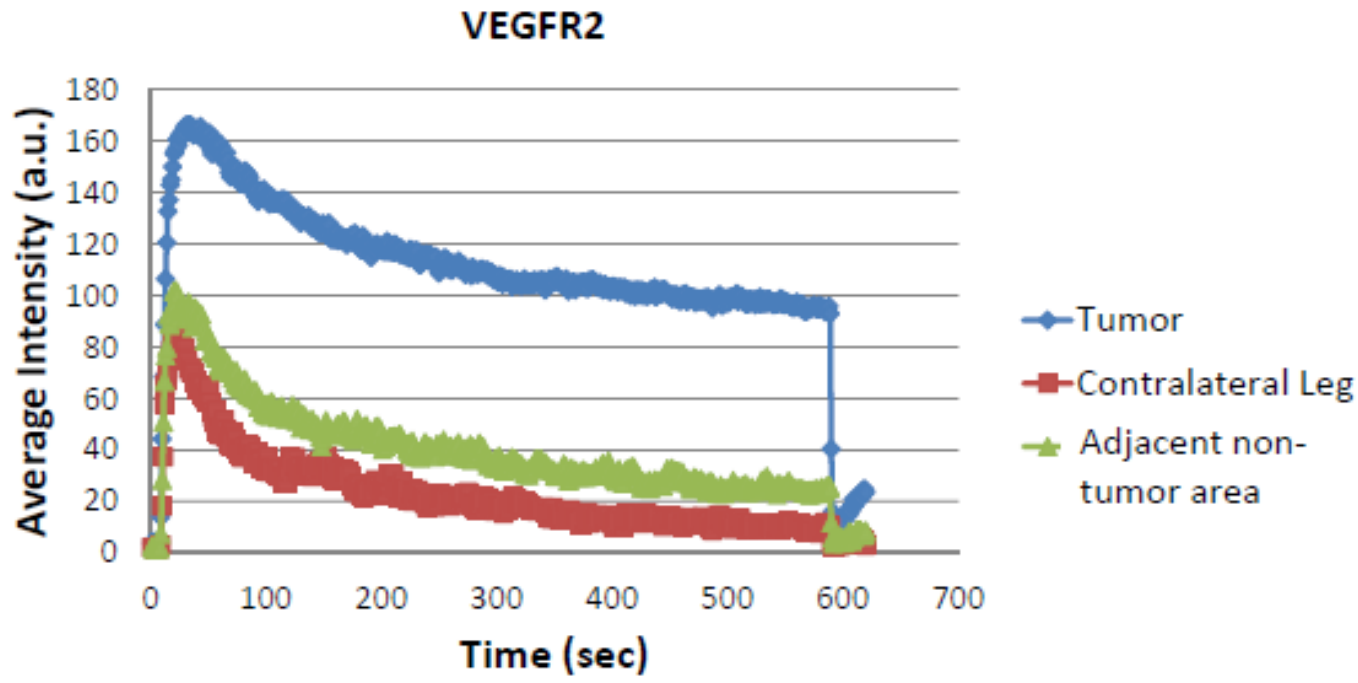

Figure 2-10: Example plot of time vs. average intensity obtained from the ultrasound images shown in Figure 2-9. 
Chapter 2: Microbubble imaging of VEGFR2 and VCAM-1 expression in B16-F1 melanoma tumors
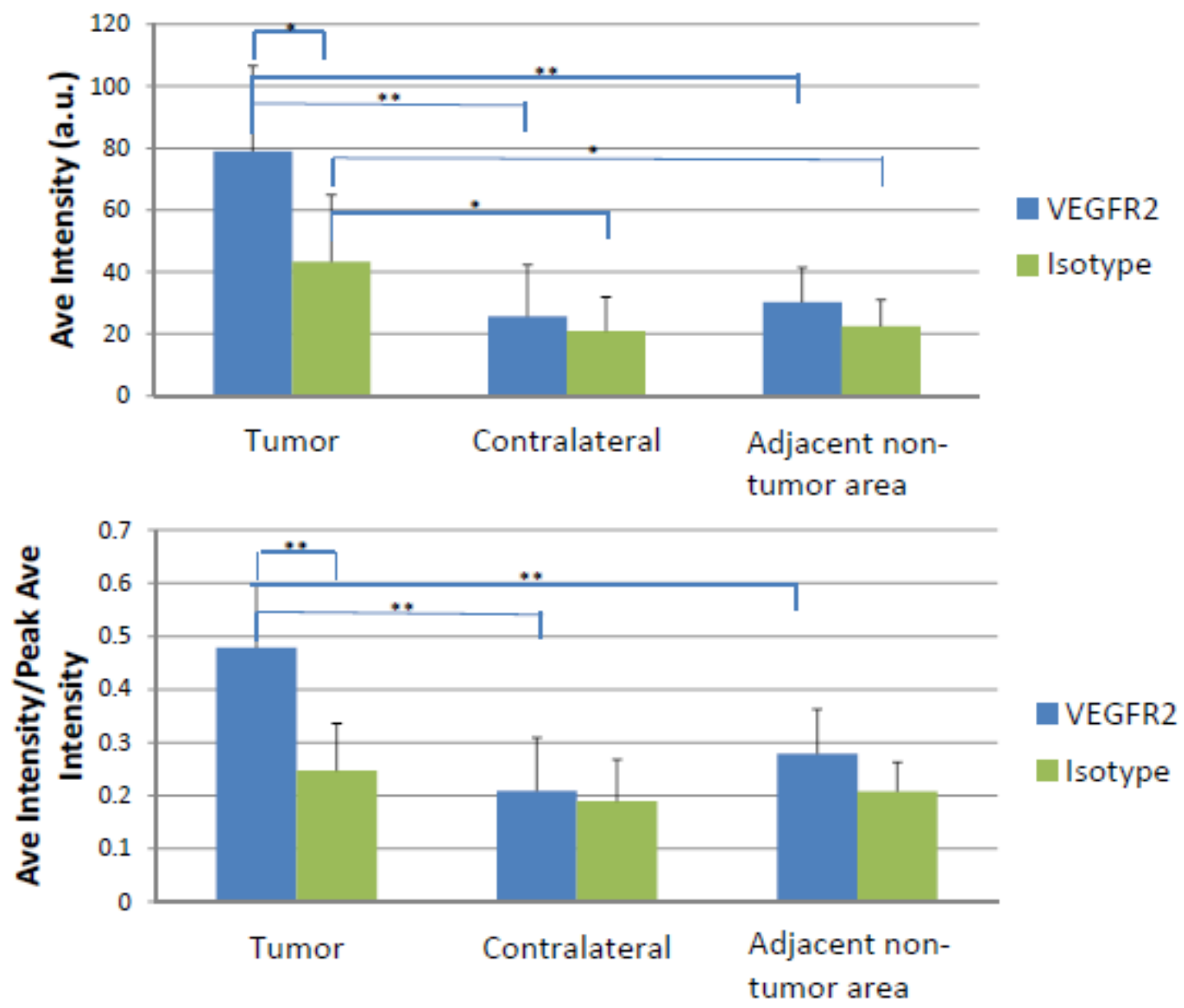

Figure 2-11: Comparison of average signal intensity of VEGFR2-targeted and control bubbles after 10 min washout in different tissues. $n=7 ;{ }^{*} p<0.05 ;{ }^{* *} p<0.01$ 

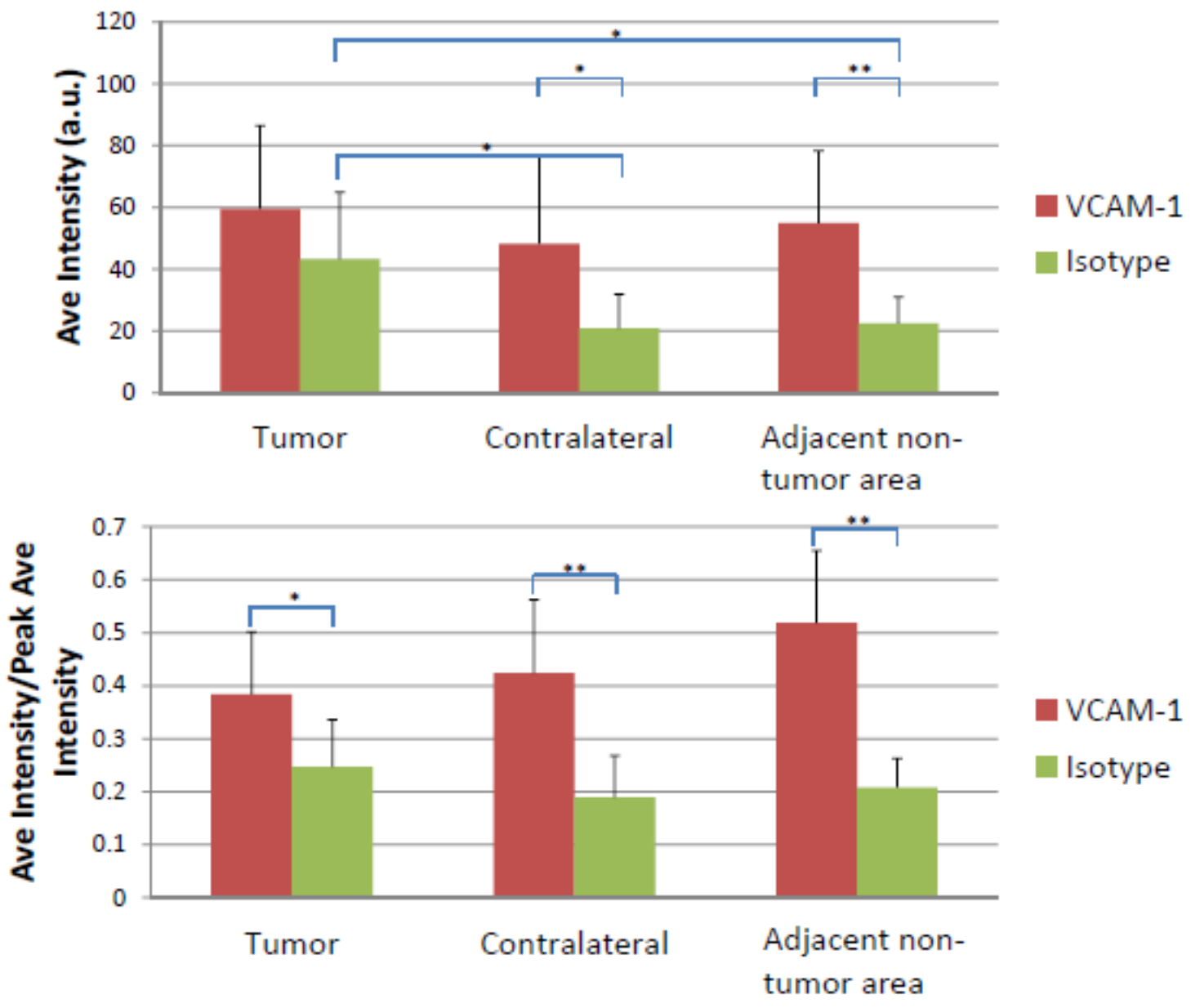

Figure 2-12: Comparison of average signal intensity of VCAM-1-targeted and control bubbles after 10 min washout in different tissues. $n=7 ;{ }^{*} p<0.05 ;{ }^{* *} p<0.01$

\section{Immunofluorescence verification of VEGFR2 expression in B16-F1 melanoma tumors}

Since VEGFR2 was shown to be a tumor-specific marker in the in vivo binding experiments, immunofluorescence was used to verify the presence of VEGFR2 on tumor endothelium. Representative pictures of tissue sections stained with VEGFR2 (Cy3), CD31 (FITC), and DAPI nuclear stain are shown in Figure 2-13. The tumor tissue had higher vascular density compared to muscle tissue (Figure 2-14). VEGFR2 expression on endothelial cells was also higher in the tumor tissue compared to adjacent nontumor tissue and contralateral leg (Figure 2-15). Endothelial VEGFR2 expression was also higher in adjacent non-tumor tissue compared to the contralateral leg, suggesting that normal tissue adjacent to 
Chapter 2: Microbubble imaging of VEGFR2 and VCAM-1 expression in B16-F1 melanoma tumors

the tumor is affected by tumor-secreted cytokines and growth factors. Interestingly, the VEGFR2/CD31 ratio was greater than 1 in tumor tissue. Possible explanations are the improved binding due to multiple epitope recognition of the polyclonal anti-VEGFR2 antibody compared to the monoclonal anti-CD31 antibody and the brightness of Cy3 compared to FITC. There were no noticeable vessels that stained positive for VEGFR2 and negative for CD31. 


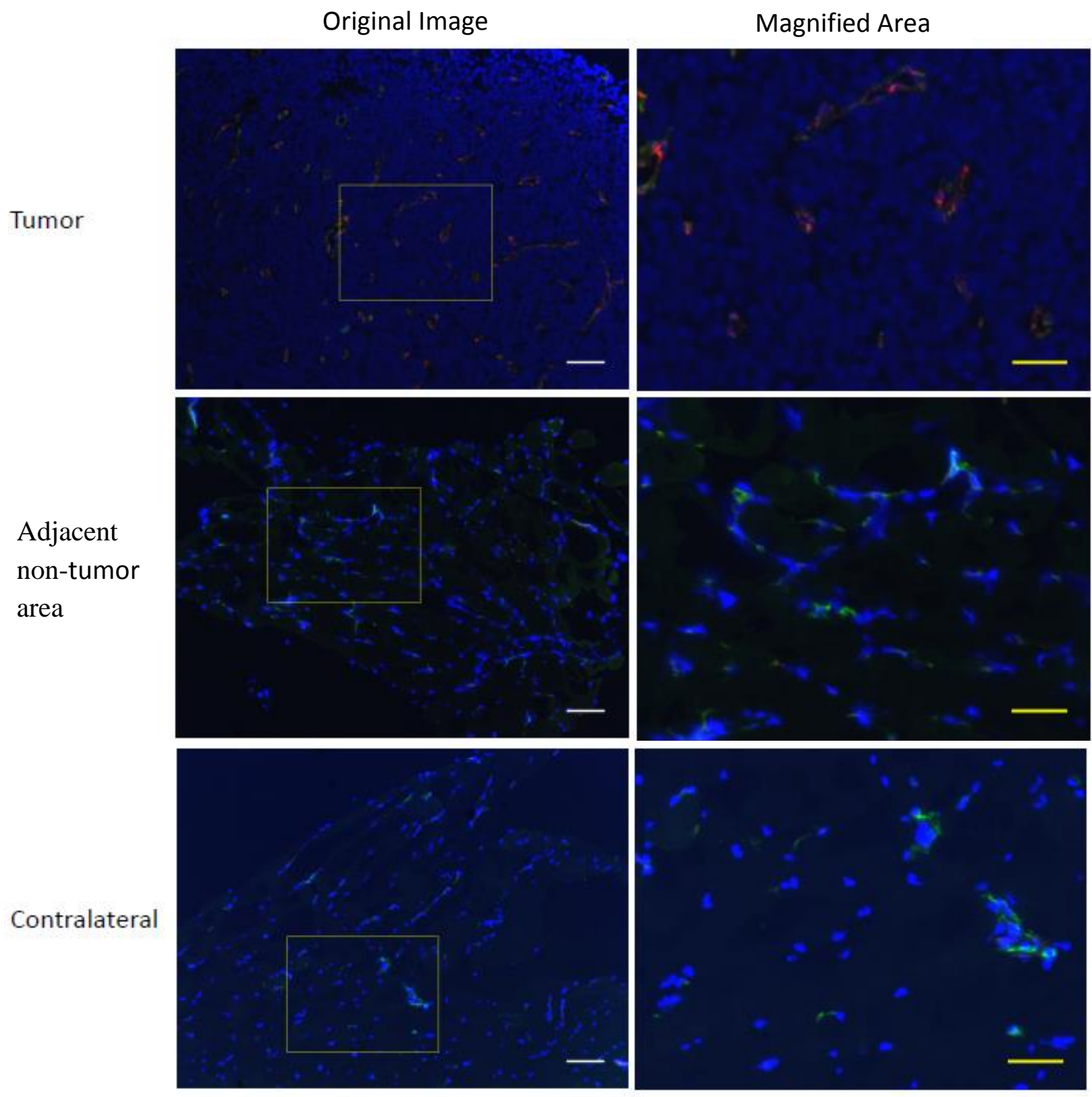

Figure 2-13: CD31 and VEGFR2 double stain in tumor, adjacent non-tumor area, and contralateral leg muscle. CD31 is represented in green, VEGFR2 is represented in red, and DAPI staining is represented in blue in pseudocolor images. The images in the right column are magnified from the yellow boxes in the left column. The yellow box is approximately $300 \times 400 \mu \mathrm{m}$. Scale bars at lower right corners are $100 \mu \mathrm{m}$ (white) or $50 \mu \mathrm{m}$ (yellow). 
Chapter 2: Microbubble imaging of VEGFR2 and VCAM-1 expression in B16-F1 melanoma tumors

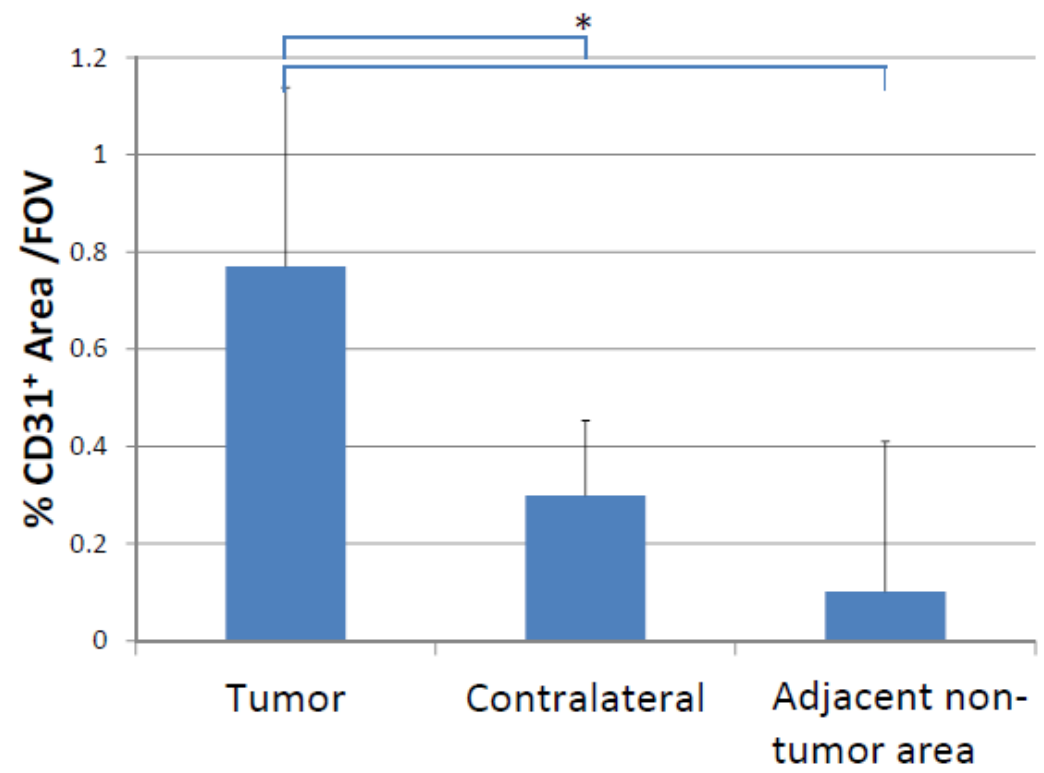

Figure 2-14: Comparison of vessel density between tumor, adjacent non-tumor tissue, and contralateral leg muscle. $n=3 ;{ }^{*} p<0.01$

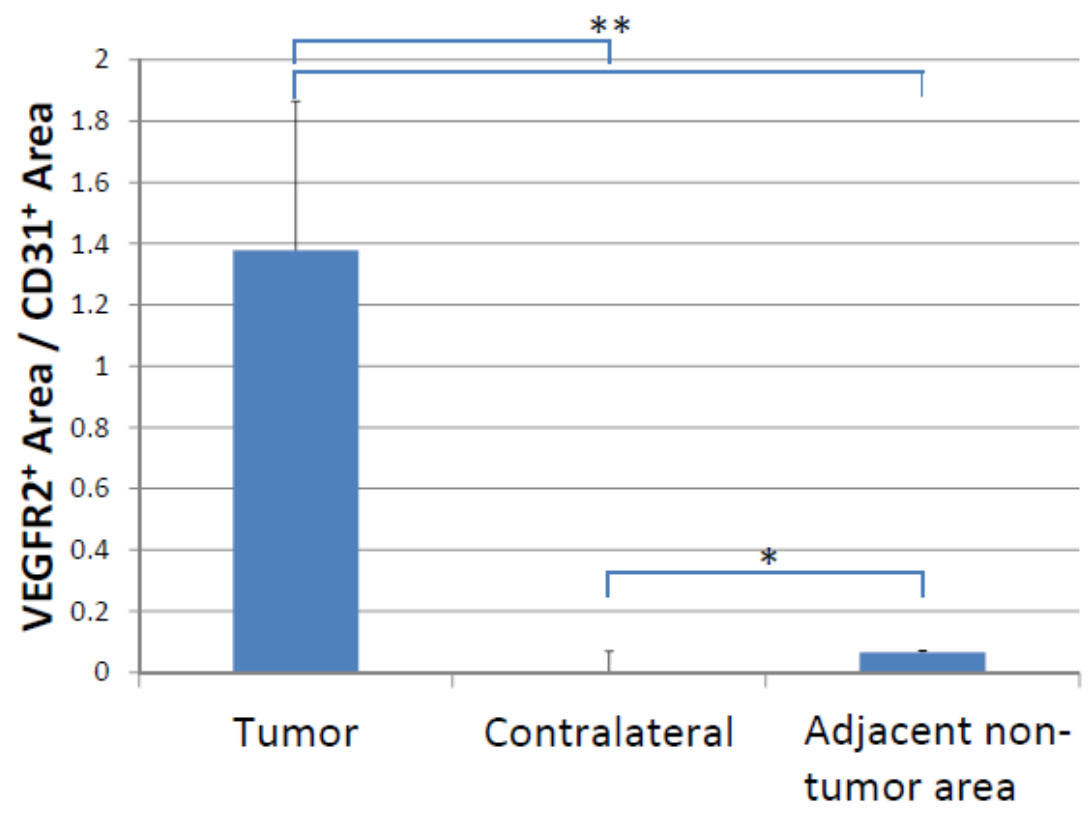

Figure 2-15: Comparison of VEGFR2 ${ }^{+}$endothelium in tumor, adjacent non-tumor tissue, and contralateral leg muscle. $n=3 ;{ }^{*} p<0.05 ;{ }^{* *} p<0.01$

\section{Discussion}


Chapter 2: Microbubble imaging of VEGFR2 and VCAM-1 expression in B16-F1 melanoma tumors

In this section, we showed that microbubbles conjugated with antibodies could be used to image B16 melanoma tumors in vivo. Tumor targeting specificity was achieved using the angiogenesis marker VEGFR2 but not with the inflammation marker VCAM-1. Previous studies (Chinnasamy et al. 2010,Gille et al. 2007) have verified the presence of VEGFR2 on B16 endothelium, but the expression pattern of VCAM-1 was not confirmed to be endothelial cell specific. VCAM-1 has been found in melanoma (Anastassiou et al. 2004,Anastassiou et al. 2000,van Duinen et al. 1994, Denton et al. 1992), but whether the expression is on endothelial cells or tumor cells has been unspecified. Few data exist regarding the relative expression of VCAM-1 and other endothelial cell specific surface markers in melanoma tissue.

Similar to observations in the MC38 mouse colon adenocarcinoma tumor model (Hernot et al. 2012), VCAM-1-targeted bubbles bound to the endothelium of melanoma tumors at a higher level than isotype control bubbles. However, VCAM-1-targeted bubbles also bound at high levels in the endothelium of contralateral and adjacent non-tumor tissue in our melanoma. Since VCAM-1 is not constitutively expressed on endothelial cells, this suggests a state of systemic inflammation. Future work would include VCAM-1-targeted microbubble imaging pre- and post-tumor induction to determine whether this systemic inflammation is caused by the melanoma tumor. Immunofluorescence co-staining of VEGFR2 and CD31 on tumor and non-tumor tissue sections confirmed tumor-specific VEGFR2 expression on endothelial cells (Figure 2-13). Comparison of the maximum intensity during bubble perfusion in tumor and non-tumor tissue suggested that the tumor had higher perfusion as suggested by higher microbubble density (Fig 2-9). The greater number of microbubbles could be due to a larger volume of blood vessels and/or more blood vessels. The greater image contrast did not suggest, however, that the microbubble transit time in the tumor region was higher. CD31 staining suggested that the tumor had a higher blood vessel density, but it was impossible to conclude whether blood vessels were on average smaller or larger than in adjacent non-tumor tissue. Nevertheless, CD31 
positive staining suggested that the tumor space was populated with endothelial cells. The flowthrough of non-targeted microbubbles and the binding of the VEGFR2-targeted microbubbles further suggested the existence of functional microvessels in a highly interconnected network in the tumor.

\section{References}

Anastassiou G, Esser M, Bader E, Steuhl KP, Bornfeld N. Expression of cell adhesion molecules and tumour infiltrating leucocytes in conjunctival melanoma. Melanoma Res 2004;14:381-5.

Anastassiou G, Schilling H, Stang A, Djakovic S, Heiligenhaus A, Bornfeld N. Expression of the cell adhesion molecules ICAM-1, VCAM-1 and NCAM in uveal melanoma: a clinicopathological study. Oncology 2000;58:83-8.

Anderson CR, Rychak JJ, Backer M, Backer J, Ley K, Klibanov AL. scVEGF microbubble ultrasound contrast agents: a novel probe for ultrasound molecular imaging of tumor angiogenesis. Invest Radiol 2010;45:579-85.

Behm CZ, Kaufmann BA, Carr C, Lankford M, Sanders JM, Rose CE, Kaul S, Lindner JR. Molecular imaging of endothelial vascular cell adhesion molecule-1 expression and inflammatory cell recruitment during vasculogenesis and ischemia-mediated arteriogenesis. Circulation 2008;117:2902-11.

Bzyl J, Lederle W, Rix A, Grouls C, Tardy I, Pochon S, Siepmann M, Penzkofer T, Schneider M, Kiessling F, Palmowski M. Molecular and functional ultrasound imaging in differently aggressive breast cancer xenografts using two novel ultrasound contrast agents (BR55 and BR38). Eur Radiol 2011;21:1988-95.

Bzyl J, Palmowski M, Rix A, Arns S, Hyvelin JM, Pochon S, Ehling J, Schrading S, Kiessling F, Lederle W. The high angiogenic activity in very early breast cancer enables reliable imaging with VEGFR2-targeted microbubbles (BR55). Eur Radiol 2013;23:468-75.

Carter PJ. Potent antibody therapeutics by design. Nat Rev Immunol 2006;6:343-57.

Chinnasamy D, Yu Z, Theoret MR, Zhao Y, Shrimali RK, Morgan RA, Feldman SA, Restifo NP, Rosenberg SA. Gene therapy using genetically modified lymphocytes targeting VEGFR-2 inhibits the growth of vascularized syngenic tumors in mice. J Clin Invest 2010;120:3953-68.

Denton KJ, Stretch JR, Gatter KC, Harris AL. A study of adhesion molecules as markers of progression in malignant melanoma. J Pathol 1992;167:187-91.

Deshpande N, Ren Y, Foygel K, Rosenberg J, Willmann JK. Tumor angiogenic marker expression levels during tumor growth: longitudinal assessment with molecularly targeted microbubbles and US imaging. Radiology 2011;258:804-11. 
Gille J, Heidenreich R, Pinter A, Schmitz J, Boehme B, Hicklin DJ, Henschler R, Breier G. Simultaneous blockade of VEGFR-1 and VEGFR-2 activation is necessary to efficiently inhibit experimental melanoma growth and metastasis formation. Int J Cancer 2007;120:1899-908.

Hernot S, Unnikrishnan S, Du Z, Shevchenko T, Cosyns B, Broisat A, Toczek J, Caveliers V, Muyldermans S, Lahoutte T, Klibanov AL, Devoogdt N. Nanobody-coupled microbubbles as novel molecular tracer. J Control Release 2012;158:346-53.

Kaufmann BA, Carr CL, Belcik JT, Xie A, Yue Q, Chadderdon S, Caplan ES, Khangura J, Bullens S, Bunting S, Lindner JR. Molecular imaging of the initial inflammatory response in atherosclerosis: implications for early detection of disease. Arterioscler Thromb Vasc Biol 2010a;30:54-9.

Kaufmann BA, Carr CL, Belcik T, Xie A, Kron B, Yue Q, Lindner JR. Effect of acoustic power on in vivo molecular imaging with targeted microbubbles: implications for low-mechanical index real-time imaging. J Am Soc Echocardiogr 2010b;23:79-85.

Kaufmann BA, Sanders JM, Davis C, Xie A, Aldred P, Sarembock IJ, Lindner JR. Molecular imaging of inflammation in atherosclerosis with targeted ultrasound detection of vascular cell adhesion molecule-1. Circulation 2007;116:276-84.

Lindner JR, Song J, Christiansen J, Klibanov AL, Xu F, Ley K. Ultrasound assessment of inflammation and renal tissue injury with microbubbles targeted to P-selectin. Circulation 2001;104:2107-12.

Palmowski M, Huppert J, Ladewig G, Hauff P, Reinhardt M, Mueller MM, Woenne EC, Jenne JW, Maurer M, Kauffmann GW, Semmler W, Kiessling F. Molecular profiling of angiogenesis with targeted ultrasound imaging: early assessment of antiangiogenic therapy effects. Mol Cancer Ther 2008;7:101-9.

Pochon S, Tardy I, Bussat P, Bettinger T, Brochot J, von Wronski M, Passantino L, Schneider M. BR55: a lipopeptide-based VEGFR2-targeted ultrasound contrast agent for molecular imaging of angiogenesis. Invest Radiol 2010;45:89-95.

Rychak JJ, Graba J, Cheung AM, Mystry BS, Lindner JR, Kerbel RS, Foster FS. Microultrasound molecular imaging of vascular endothelial growth factor receptor 2 in a mouse model of tumor angiogenesis. Mol Imaging 2007;6:289-96.

Tardy I, Pochon S, Theraulaz M, Emmel P, Passantino L, Tranquart F, Schneider M. Ultrasound molecular imaging of VEGFR2 in a rat prostate tumor model using BR55. Invest Radiol 2010;45:573-8.

van Duinen CM, van den Broek LJ, Vermeer BJ, Fleuren GJ, Bruijn JA. The distribution of cellular adhesion molecules in pigmented skin lesions. Cancer 1994;73:2131-9.

Warram JM, Sorace AG, Saini R, Umphrey HR, Zinn KR, Hoyt K. A triple-targeted ultrasound contrast agent provides improved localization to tumor vasculature. J Ultrasound Med 2011;30:921-31.

Weissleder R, Kelly K, Sun EY, Shtatland T, Josephson L. Cell-specific targeting of nanoparticles by multivalent attachment of small molecules. Nat Biotechnol 2005;23:1418-23. 
Willmann JK, Lutz AM, Paulmurugan R, Patel MR, Chu P, Rosenberg J, Gambhir SS. Dual-targeted contrast agent for US assessment of tumor angiogenesis in vivo. Radiology 2008;248:936-44.

Wu J, Leong-Poi H, Bin J, Yang L, Liao Y, Liu Y, Cai J, Xie J, Liu Y. Efficacy of contrast-enhanced US and magnetic microbubbles targeted to vascular cell adhesion molecule-1 for molecular imaging of atherosclerosis. Radiology 2011;260:463-71. 


\section{Chapter 3: Targeted transfection of B16-F1 melanoma tumors using a RFP reporter gene}

\section{Introduction}

In the previous chapter, VEGFR2-targeted microbubbles were shown to bind specifically to the endothelium of B16-F1 melanomas. This chapter will focus on delivering a reporter gene to the tumor using ultrasound-mediated destruction of VEGFR2-targeted microbubbles.

There are several ways to deliver therapeutic genes to target tissue using microbubbles. If the desired area of delivery is known, targeting can be achieved via placement of the transducer so that microbubble destruction only occurs in that area (Phillips et al. 2010b,Chen et al. 2010,Burke et al. 2012,Sirsi et al. 2012,Carson et al. 2012,Christiansen et al. 2003,Panje et al. 2012,Bekeredjian et al. 2003). Further targeting specificity can be obtained via plasmid design such as the use of cell specific promoters (Chen et al. 2006). Another option is direct injection of the bubbles and plasmid to the desired area followed by insonation(Li et al. 2009). This option is less practical since the area may not be readily accessible, and the procedure is also more invasive. Lastly, targeted delivery can be achieved using molecular targeting (Tlaxca et al. 2013,Xie et al. 2012). Targeting ligands can be attached to the microbubble surface so that bubble binding is limited to the vasculature of the area of interest. We will be using this method of targeting since it has several advantages. First, there is no need of a second imaging modality to guide the beam placement of the ultrasound. Since bubble binding is specific to the tumor, transfection of adjacent healthy tissue will not occur even if the tissue is insonated by the ultrasound beam. Second, VEGFR2-targeting may be used for the delivery of therapeutic genes to small tumors in the early phase of angiogenesis that are not easily detected using non-molecular imaging methods.

The therapeutic plasmid to be delivered can be packaged in several ways. Simple co-injection of plasmid and bubble mixtures has been used for in vivo transfection (Li et al. 2009). The disadvantage is that naked DNA has a short half-life in circulation. This problem can be ameliorated through the use of 
Chapter 3: Targeted transfection of B16-F1 melanoma tumors using a RFP reporter gene

PEGylated (Burke et al. 2012) or non-PEGlyated polymers (Chen et al. 2010) to form nanoparticles with DNA. Alternatively, the negative charge of plasmids can be used to attach them to cationic microbubbles (Phillips et al. 2010b,Carson et al. 2012,Christiansen et al. 2003, Tlaxca et al. 2013,Xie et al. 2012,Phillips et al. 2010a,Shohet et al. 2000). The PEG brush on the bubbles then confers protection against nucleases. Plasmid can also be coupled to the bubble shell using cationic polymers (Sirsi et al. 2012,Borden et al. 2007) and bubble liposomes (Chen et al. 2003,Suzuki et al. 2008). In this chapter, we will be using charge coupling to attach plasmid to microbubbles as a proof of concept for targeted gene delivery to B16 melanoma tumors. If the DNA payload or transfection efficiency needs to be improved, we will explore the use of cationic polymers such as PEI in future work.

\section{Methods and materials}

\section{Ultrasound intensity measurement for transducer characterization}

A Birtcher Megason VI Model 106-5 (Birtcher Corp., Los Angeles, CA) ultrasound machine with a center frequency of $1 \mathrm{MHz}$ was used for transfection. For characterization, the ultrasound intensity was measured for each numbered dial position on the machine. Radiation force exerted on a rubber acoustic absorber was measured and converted to power using the following equation: $P=c F$, where $\mathrm{P}$ is power $(\mathrm{W}), \mathrm{c}$ is the speed of sound $\left(1491 \mathrm{~m} / \mathrm{s}\right.$ in water at $\left.23^{\circ} \mathrm{C}\right)$, and $\mathrm{F}$ is force $(\mathrm{N})$. Power was then converted to intensity by dividing by the transducer area $\left(5 \mathrm{~cm}^{2}\right)$.

Figure 3-1 shows the experimental setup for radiation force measurement. The transducer was positioned to exert radiation force on a rubber acoustic absorber submerged in a water bath on top of a scale. The readout from the scale was then converted to force using the equation $F=9.8 \mathrm{~m}$, where $\mathrm{m}$ is the readout in $\mathrm{kg}$. The distance between the transducer and the top surface of the rubber acoustic absorber was kept at $1 \mathrm{~cm}$. The water was degassed via 15 min incubation in a sonicator bath under 
vacuum. All measurements were taken $15 \mathrm{sec}$ after the transducer was turned on, and the measurement for each numbered dial position was repeated four times and averaged.

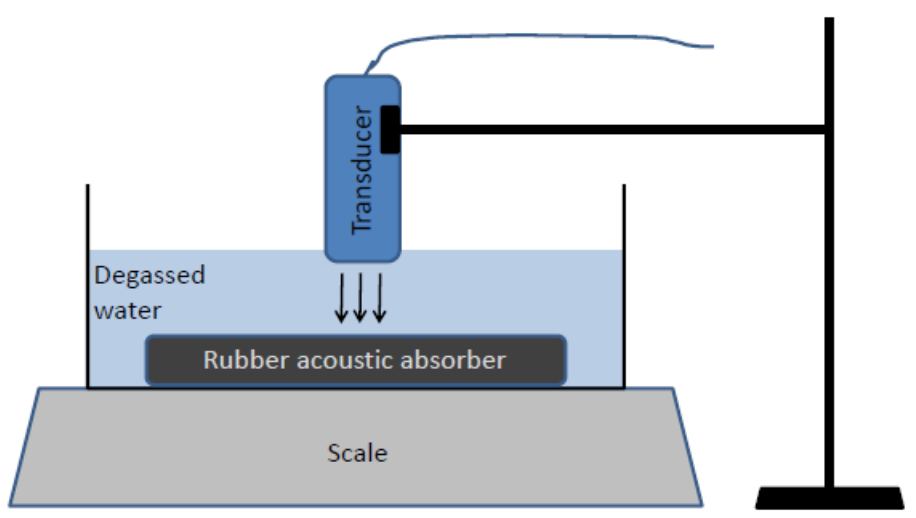

Figure 3-1: Experimental setup for transducer intensity measurement

\section{Reporter plasmid preparation}

Two reporter plasmids were used for the transfection studies, and both were propagated in Subcloning Efficiency DH5a Competent Cells (Life Technologies, Grand Island, NY). Kanamycin (Life Technologies, Grand Island, NY) was used as a selection agent at $30 \mu \mathrm{g} / \mathrm{mL}$ for the red fluorescent protein (RFP) encoding plasmid pTurboRFP-C (Evrogen, Moscow, Russia). Ampicillin (Teknova, Hollister, CA) was used at $50 \mu \mathrm{g} / \mathrm{mL}$ as a selection agent for the green fluorescent protein (GFP) encoding plasmid pACMVeGFP. A QIAGEN Plasmid Giga Kit (Qiagen, Valencia, CA) was used to purify plasmids from E.Coli according to the manufacturer's instructions. Purified plasmids were suspended in a Tris-EDTA (TE) buffer composed of $10 \mathrm{mM}$ Tris (Sigma-Aldrich, St. Louis, MO) and 1 mM EDTA (Sigma-Aldrich, St. Louis, $\mathrm{MO}$ ) and adjusted to $\mathrm{pH}$ 8.0. Plasmid concentration was determined using absorbance measured at 260 nm using an ND1000 NanoDrop Spectrophotometer (Fisher Thermo Scientific, Waltham, MA).

In vitro transfection of HEK293 cells using microbubbles and ultrasound

\section{Cell culture}


Chapter 3: Targeted transfection of B16-F1 melanoma tumors using a RFP reporter gene

The human embryonic kidney 293 (HEK-293) cell line was used to validate transfection via sonoporation in vitro. $\mathrm{HEK}-293$ cells were kept at $37^{\circ} \mathrm{C}$ in $5 \% \mathrm{CO}_{2}$ environment and maintained in DMEM with high glucose supplemented with $1 \mathrm{mM}$ sodium pyruvate, $10 \%$ fetal FBS, and $1 \%$ penicillin/streptomycin (Invitrogen, Grand Island, NY). For transfection experiments, cells were seeded in acoustically transparent OptiCell chambers (Thermo Fisher Scientific, Waltham, MA) and grown to $80 \%$ confluence.

\section{Sonoporation}

For transfection, microbubbles were first washed 3 times to remove free lipid. $20 \mu \mathrm{g}$ of pACMVeGFP plasmid was mixed with $4 \times 10^{8}$ microbubbles (total volume less than $1 \mathrm{~mL}$ ), injected into an OptiCell, and then mixed thoroughly with the cell culture medium already in the OptiCell chamber. The OptiCell was placed in a water bath with the cell-seeded side on top. A 2 min incubation period allowed for bubbles to float up towards the cells. The transducer was then placed at a $5 \mathrm{~cm}$ distance from the OptiCell surface and switched on to transfect the cells. A water-filled OptiCell was placed $5 \mathrm{~cm}$ from the seeded OptiCell to serve as a guide for the transducer so that the $5 \mathrm{~cm}$ separation distance could be maintained while moving the transducer to insonate the entire cell-seeded surface. The setup can be seen in Figure 3-2. Two hr after transfection, the cell culture medium was changed. Cells were observed for GFP fluorescence $24 \mathrm{hr}$ after transfection using an Eclipse TE300 microscope (Nikon Instruments, Melville, NY) and imaged using a VIXIA HF S21 camcorder (Canon, Melville, NY). For analysis, the number of GFP positive cells in 3 random fields of view was counted for each OptiCell. 


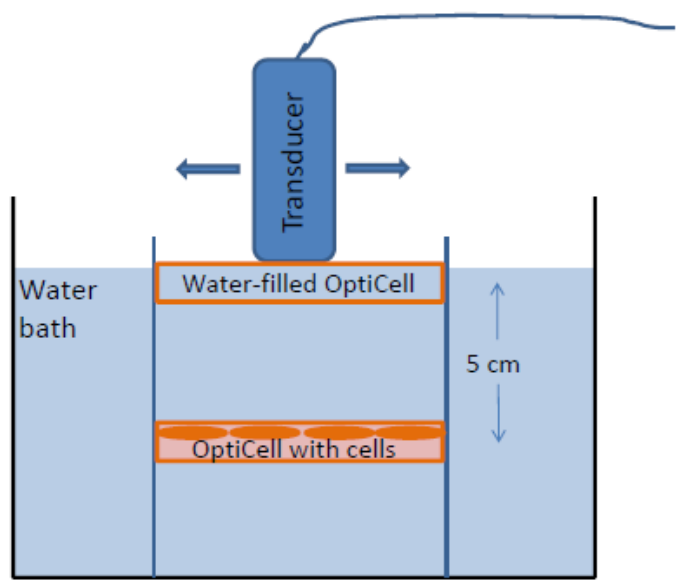

Figure 3-2: Transducer placement for in vitro sonoporation experiment

In vivo transfection of B16-F1 melanomas using VEGFR2-targeted microbubbles

\section{Preparation of plasmid-carrying, VEGFR2-targeted microbubbles}

Microbubbles containing the lipid 1,2-distearoyl-3-trimethylammoniumpropane (DTAP) in their shells to provide a net positive charge were used to carry negatively charged plasmid. These cationic bubbles were biotinylated, and anti-VEGFR2 antibody was conjugated using the procedure described in Chapter 2. pTurboRFP-C plasmid was then added to the bubble solution at $15 \mu \mathrm{g} / 10^{8} \mathrm{MB}$ and incubated for 10 minutes at room temperature to allow plasmid binding through charge interactions. The bubbles were then washed 3 times to remove unbound plasmid.

To measure the payload of cationic microbubbles, the bubble solution was left overnight in a water bath set at $65^{\circ} \mathrm{C}$ to dissolve the bubble shell. The absorbance at $260 \mathrm{~nm}$ was then measured using the ND1000 NanoDrop Spectrophotometer to determine plasmid concentration.

\section{In vivo transfection using VEGFR2-targeted microbubbles}

The in vivo transfection procedure was the same as the in vivo imaging procedure written in Chapter 2. After the 10 min washout period, the Megason VI transducer was used to burst bubbles in 
Chapter 3: Targeted transfection of B16-F1 melanoma tumors using a RFP reporter gene

both the tumor-bearing leg and the contralateral leg at a setting of 3 , which corresponds to an intensity of $0.37 \mathrm{~W} / \mathrm{cm}^{2}$. After a $15 \mathrm{sec}$ warm-up period, the transducer was manually moved over each leg for 10 sec/leg. The Sequoia ultrasound system with $15 \mathrm{~L} 8$ transducer was used before and after transfection to monitor the binding and the destruction of plasmid-bearing targeted microbubbles. The non-destructive bubble imaging parameters described in Chapter 2 (Cadence CPS mode with $7 \mathrm{MHz}$ ultrasound frequency, $\mathrm{MI}=0.20$, and a dynamic range of $50 \mathrm{~dB}$ ) were utilized. $48 \mathrm{hr}$ after transfection, mice were euthanized using via ketamine overdose, and the tumor was removed so that RFP expression could be assessed using immunohistochemical staining.

\section{Immunohistochemical staining for quantification of transfection efficiency}

Since the RFP produced from the delivered plasmid was a cytosolic protein, tissue had to be fixed in formalin to prevent the RFP from leaching out during tissue processing in preparation for microscopy. Formalin fixation increases background autofluorescence, so instead of looking for fluorescence, an enzyme-conjugated antibody against RFP was used for colorimetric detection. Immunofluorescence is usually preferred for co-staining since the colored product from the enzyme attached to the first antibody is amplified so much that it can mask binding sites for the primary antibody to the second antigen. However, co-staining is possible using the immunoenzymatic method when the two antigens are on different cells or are localized to different cellular components (ex: nuclear, cytoplasmic, or cell membrane-bound).

\section{Tissue preparation}

Two days after transfection, mice were euthanized by intraperitoneal administration of ketamine. Tumor tissue was removed and fixed overnight in $10 \%$ neutral buffered formalin (Avantor Performance Materials, Center Valley, PA) at room temperature. The tissue was then washed twice via one hour incubations in DPBS at $4^{\circ} \mathrm{C}$ before being embedded in O.C.T. compound and flash frozen in 


\section{Chapter 3: Targeted transfection of B16-F1 melanoma tumors using a RFP reporter gene}

liquid nitrogen. $7 \mu \mathrm{m}$ thick sections were cut in a cryostat set at $-23^{\circ} \mathrm{C}$ and adhered to Fisherbrand SuperFrost Plus microscope slides (Thermo Fisher Scientific, Waltham, MA). Slides were dried for $2 \mathrm{hr}$ at room temperature before staining or storage at $-80^{\circ} \mathrm{C}$. To evaluate the specificity of gene delivery, contralateral leg muscle, the spleen, liver, and kidneys were also removed and processed using the same procedure.

\section{Antibodies used}

For CD31 staining, the antibodies used were an IgG2a rat anti-mouse CD31 antibody (Clone SZ31; Dianova GmbH, Hamburg, Germany) and an alkaline phosphatase-conjugated donkey anti-rat IgG secondary antibody (Jackson ImmunoResearch Laboratories, West Grove, PA). The VECTOR Blue alkaline phosphatase substrate kit (Vector Laboratories, Burlingame, CA) was used to develop a blue colored stain in the presence of alkaline phosphatase. The kit components were added to a $0.1 \mathrm{M}$ Tris buffer $(\mathrm{pH}$ 8.4), which was prepared by combining $5.28 \mathrm{~g} / \mathrm{L}$ of TRIZMA-HCl (Sigma-Aldrich, St. Louis, MO) and 8.06 g/L of TRIZMA base (Sigma-Aldrich, St. Louis, MO) in Milli-Q water. 0.1\% Tween-20 (Sigma-Aldrich, St. Louis, MO) was added to the Tris buffer as suggested by the manufacturer.

For RFP staining, the antibodies used were a rabbit polyclonal anti-tRFP antibody (Evrogen, Moscow, Russia) and a horse radish peroxidase-conjugated horse anti-rabbit secondary antibody from the ImmPRESS anti-rabbit Ig polymer detection kit (Vector Laboratories, Burlingame, CA). The ImmPACT NovaRED peroxidase substrate kit (Vector Laboratories, Burlingame, CA) was used to develop a brownish red color in the presence of peroxidase.

\section{Staining procedure}

Heat induced epitope retrieval was necessary for successful CD31 staining. Slides were immersed in a Tris-EDTA buffer solution at $\mathrm{pH}$ 9, for $20 \mathrm{~min}$ at $100^{\circ} \mathrm{C}$ on a hotplate. The Tris-EDTA buffer 
Chapter 3: Targeted transfection of B16-F1 melanoma tumors using a RFP reporter gene

comprised of 10 mM TRIZMA Base (Sigma-Aldrich, St. Louis, MO), 1 mM EDTA (Sigma-Aldrich, St. Louis, MO), and 0.05\% Tween-20 (Sigma-Aldrich, St. Louis, MO) in Milli-Q water. After heating, the slides were allowed to cool to room temperature for $20 \mathrm{~min}$ and then washed twice for $5 \mathrm{~min}$ each. A solution of $0.1 \%$ saponin (MP Biomedicals, Santa Ana, CA) in DPBS (Invitrogen, Grand Island, NY) was used for all washing steps during this procedure.

Next, endogenous enzyme activity was quenched via a 10 min incubation in BLOXALL endogenous peroxidase and alkaline phosphatase blocking solution (Vector Laboratories, Burlingame, CA) followed by a 5 min wash. Tissue sections were then incubated with $2.5 \%$ normal horse serum included in the ImmPRESS anti-rabbit Ig polymer detection kit for 20 min at room temperature to block non-specific binding. After a 5 min wash, sections were incubated with anti-CD31 primary antibody at 1:20 dilution for $45 \mathrm{~min}$ in a humidity chamber. Slides were then washed for $5 \mathrm{~min}$ before incubation with alkaline phosphatase-conjugated secondary antibody at a 1:50 dilution. After a 5 min wash, slides were incubated with VECTOR blue substrate for $30 \mathrm{~min}$. The reaction was quenched via a 5 min wash, and the staining procedure was repeated from the primary antibody incubation step for RFP staining. Anti-tRFP antibody was diluted 1:500 for staining and the secondary antibody was used undiluted from the ImmPRESS kit. Tissue sections were incubated for $20 \mathrm{~min}$ in NovaRED substrate solution.

After staining, sections were dehydrated and cleared via a 1 min incubation in $70 \%$ ethanol, followed by a 1 min incubation in $100 \%$ ethanol, and then a 2 min incubation in the xylene substitute Histo-Clear (National Diagnostics, Atlanta, GA). Slides were mounted using VectaMount permanent mounting medium (Vector Laboratories, Burlingame, CA).

\section{Image analysis}


Chapter 3: Targeted transfection of B16-F1 melanoma tumors using a RFP reporter gene

Brightfield images were taken using a 60x oil immersion objective on an Eclipse TE300

microscope (Nikon Instruments, Melville, NY) and a VIXIA HF S21 camcorder (Canon, Melville, NY). Photos were saved as JPEG images.

To analyze the correlation between RFP expression and distance from blood vessels, CD31 positive areas were identified in the brightfield images and ROI's were drawn in ImageJ software to include the area within $10 \mu \mathrm{m}$ of blood vessels (Figure 3-3A). Next, color thresholding in the hue, saturation, and brightness (HSB) color space was used to isolate out and draw ROI's around the brownish red $\mathrm{RFP}^{+}$area (Figure 3-3B). The two ROI were then combined using the AND function (Figure 3-3C) and used to calculate the total $\mathrm{RFP}^{+}$area within $10 \mu \mathrm{m}$ of a blood vessel. A similar strategy was used to calculate the total $\mathrm{RFP}^{+}$area within $10-20 \mu \mathrm{m}$ distance of a blood vessel. 
A ROI drawn around area within $10 \mu \mathrm{m}$ of blood vessel

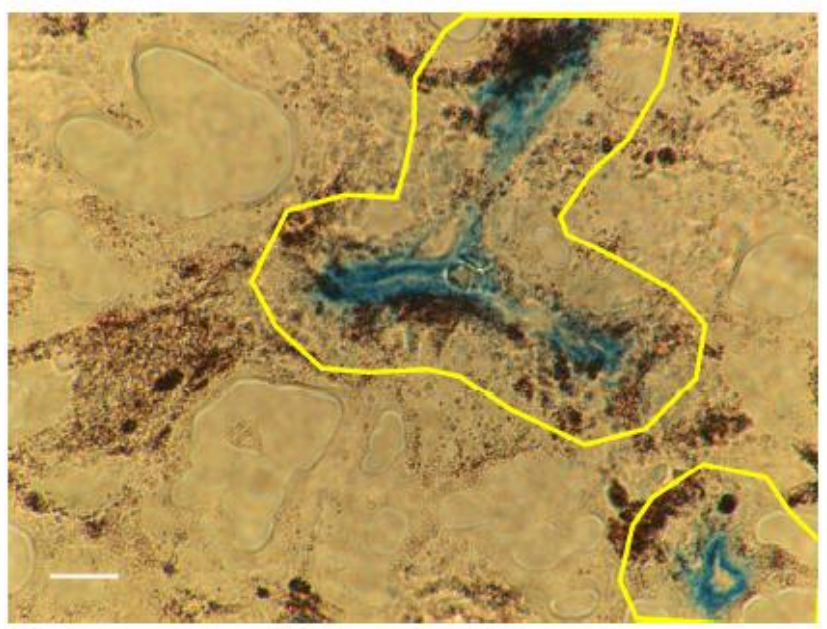

B ROI drawn around $\mathrm{RFP}^{+}$area using color thresholding

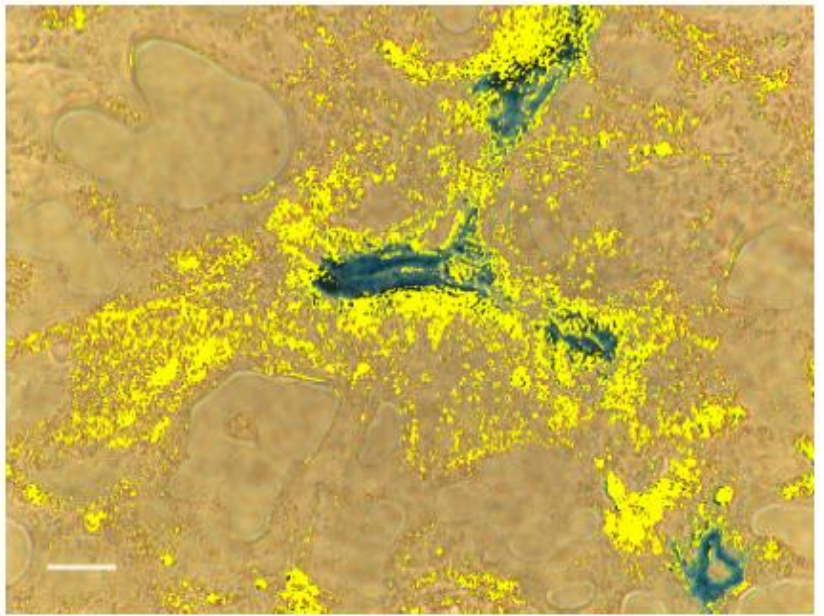

C Combined ROI's

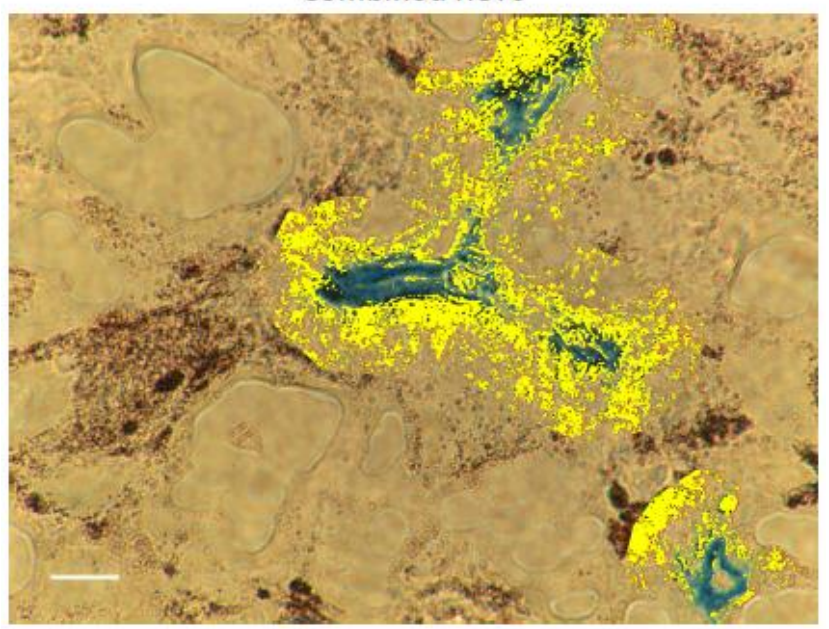

Figure 3-3: Method for measuring RFP $^{+}$area within $10 \mu \mathrm{m}$ of blood vessels. Scale bar: $10 \mu \mathrm{m}$. 


\section{Results}

\section{Ultrasound intensity measurement}

Figure 3-4 shows the intensity measured at each dial position. The Megason VI ultrasound was able to generate up to $5.2 \mathrm{~W} / \mathrm{cm}^{2}$ in intensity. This range covers the intensities that have been applied successfully for in vivo transfection in other studies (Chen et al. 2010,Sirsi et al. 2012,Panje et al. 2012,Li et al. 2009, Tlaxca et al. 2013). The intensity increased nonlinearly with the dial. At high intensities, the rubber acoustic absorber became heated within 1-2 min of insonation with $100 \%$ duty cycle.

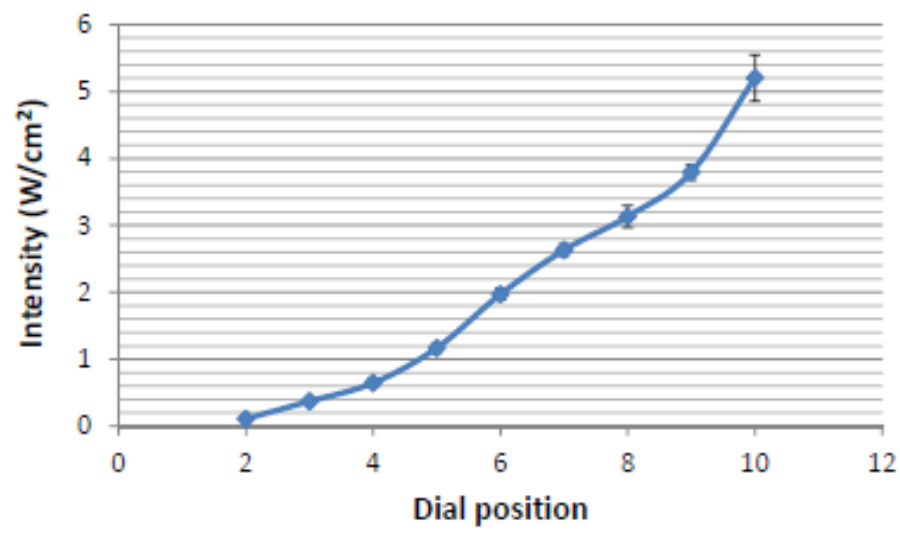

\begin{tabular}{|c|c|c|}
\hline Dial position & $\begin{array}{l}\text { Ave Intensity } \\
\left(\mathrm{W} / \mathrm{cm}^{\wedge} 2\right)\end{array}$ & $\begin{array}{l}\text { Standard } \\
\text { deviation }\end{array}$ \\
\hline 2 & $2 \quad 0.11$ & 0.01 \\
\hline 3 & 0.37 & 0.01 \\
\hline 4 & 0.65 & 0.05 \\
\hline 5 & 1.17 & 0.07 \\
\hline 6 & 1.97 & 0.08 \\
\hline 7 & 2.63 & 0.09 \\
\hline 8 & 3.13 & 0.16 \\
\hline 9 & 3.79 & 0.11 \\
\hline 10 (max) & 5.20 & 0.35 \\
\hline
\end{tabular}

Figure 3-4: Ultrasound intensity measurement

\section{In vitro transfection of HEK-293 cells}

GFP expression was significantly higher in insonated cells vs. cells that were incubated with the plasmid-bubble mixture but were not insonated. Although transfection did occur at $0.11 \mathrm{~W} / \mathrm{cm}^{2}$, transfection efficiency was much greater at $0.65 \mathrm{~W} / \mathrm{cm}^{2}$ and higher settings. There was no difference in transfection efficiency at intensities greater than or equal to $0.65 \mathrm{~W} / \mathrm{cm}^{2}$. Cell death did occur in the insonated cells, especially at high intensities such as setting 10 . Some cells detached in sheets a few minutes after insonation whereas control cells that were not insonated remained attached to the OptiCell surface. Although the temperature of the water bath increased during the transducer 
characterization experiment, no change in temperature was detected during in vitro transfection and subsequent in vivo transfection experiments.
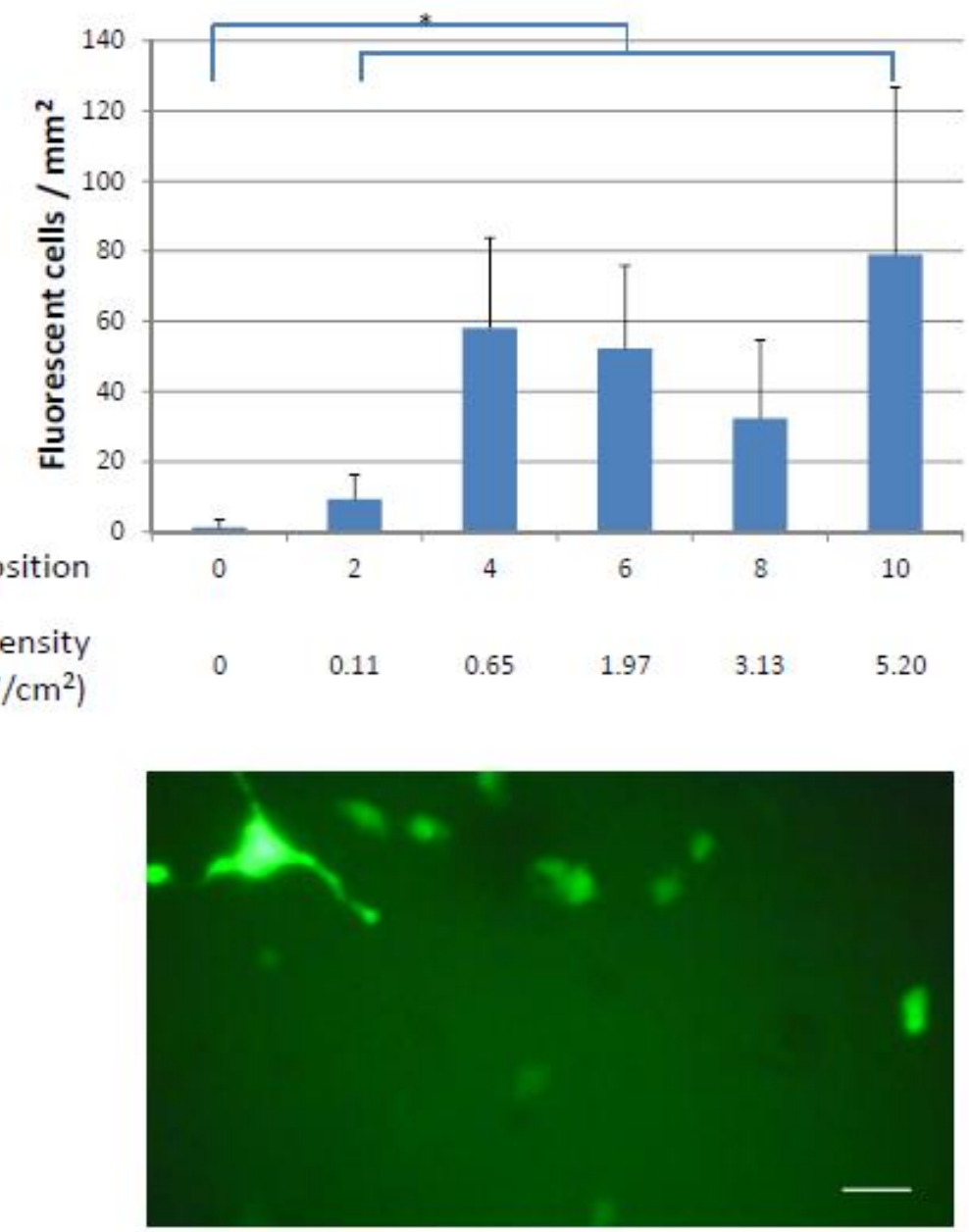

Figure 3-5: GFP transfection of HEK-293 cells in OptiCell chambers using sonoporation. Figure on the bottom shows an example fluorescence image of cells transfected using setting $10\left(5.20 \mathrm{~W} / \mathrm{cm}^{2}\right)$ on the dial. The scale bar represents $50 \mu \mathrm{m} .{ }^{*} \mathrm{p}<0.01, \mathrm{n}=3$

\section{In vivo transfection of B16-F1 melanomas using VEGFR2-targeted microbubbles}

Results from measuring the DNA payload of cationic microbubbles are shown in Figure 3-6.

Since plasmid binding to the microbubble surface was saturated at an incubation ratio of $15 \mu \mathrm{g}$ of DNA /

$10^{8} \mathrm{MB}$, this incubation ratio was used to prepare bubbles for in vivo transfection experiments. $1.29 \pm$

$0.23 \mu \mathrm{g}$ of DNA were attached per $10^{8} \mathrm{MB}$. 


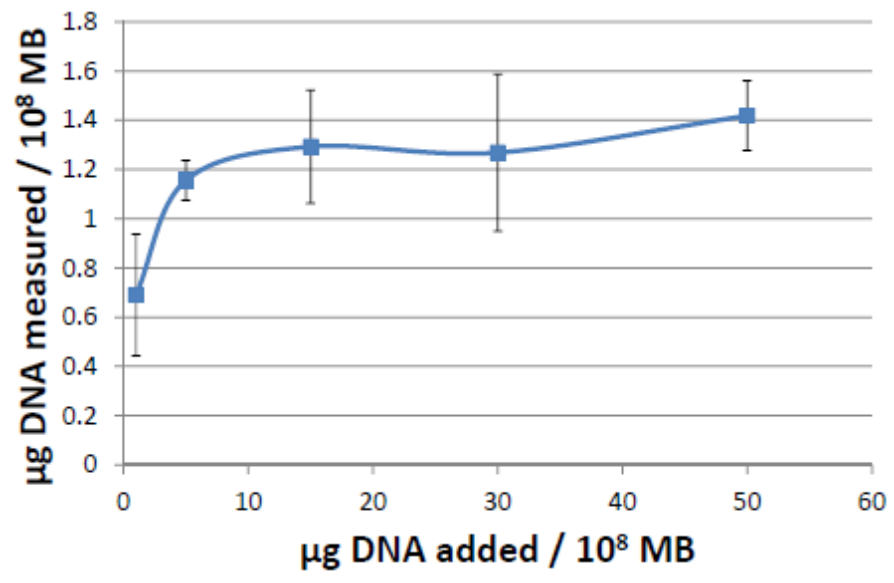

Figure 3-6: Measurement of the DNA payload of cationic microbubbles. $n=3$.

In an exploratory experiment involving VEGFR2-targeted cationic microbubbles carrying plasmid and the cationic polymer PEl, setting $9\left(3.79 \mathrm{~W} / \mathrm{cm}^{2}\right)$ was tested for repeated transfection to maximize plasmid delivery (Tlaxca et al. 2013). The single transfection protocol described in the methods section was repeated with intervals of $10 \mathrm{~min}$ in between to allow for clearance of microbubbles from the previous injection. A non-perfused region was observed in the tumor (Figure 3-7) after the second round of transfection. It was later determined that a necrotic core was created by the repeated insonation with PEI-complexed plasmid. To avoid the possible negative effects of blood vessel occlusion or mechanical disruption of the tumor tissue on cell viability and plasmid gene expression, the intensity setting used for later transfection experiments was decreased to $0.37 \mathrm{~W} / \mathrm{cm}^{2}$, and sonoporation was limited to once instead of multiple times. 


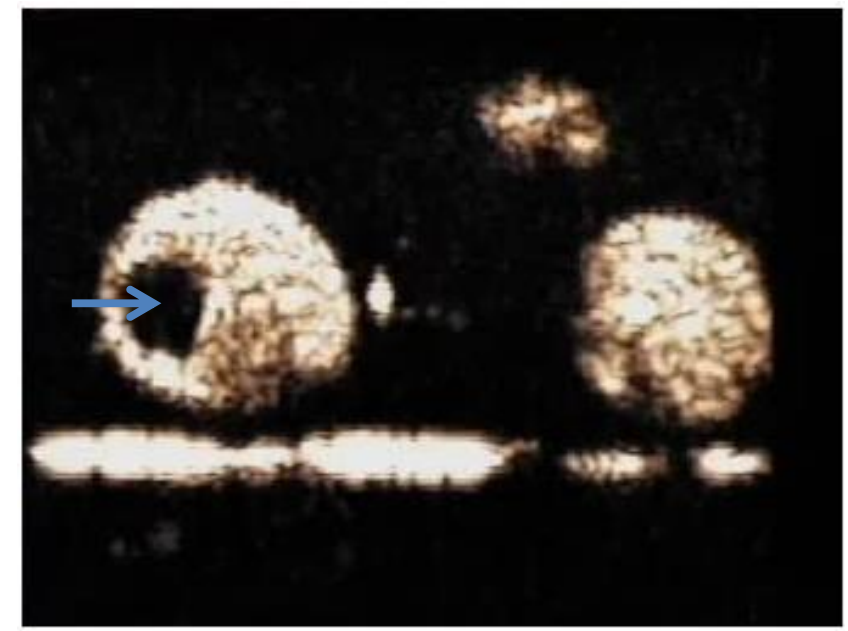

Figure 3-7: Non-perfused area (blue arrow) observed in the tumor after repeated ultrasoundmediated destruction of microbubbles.

Tumor and adjacent muscle tissue insonatated after microbubble retention using the lower intensity setting was stained for RFP using immunohistochemistry (Figure 3-8). Tumor tissue stained positive for RFP while there was little to no staining in adjacent muscle tissue. Tissue sections were costained for CD31 to determine whether tumor cells or endothelial cells were being transfected and to identify vascularized sections of the melanoma tumor. A majority of the RFP positive cells were within $10 \mu \mathrm{m}$ of a blood vessel (Figure 3-9). However, there were some areas that stained positive for RFP but were not close to a CD31 positive area. 

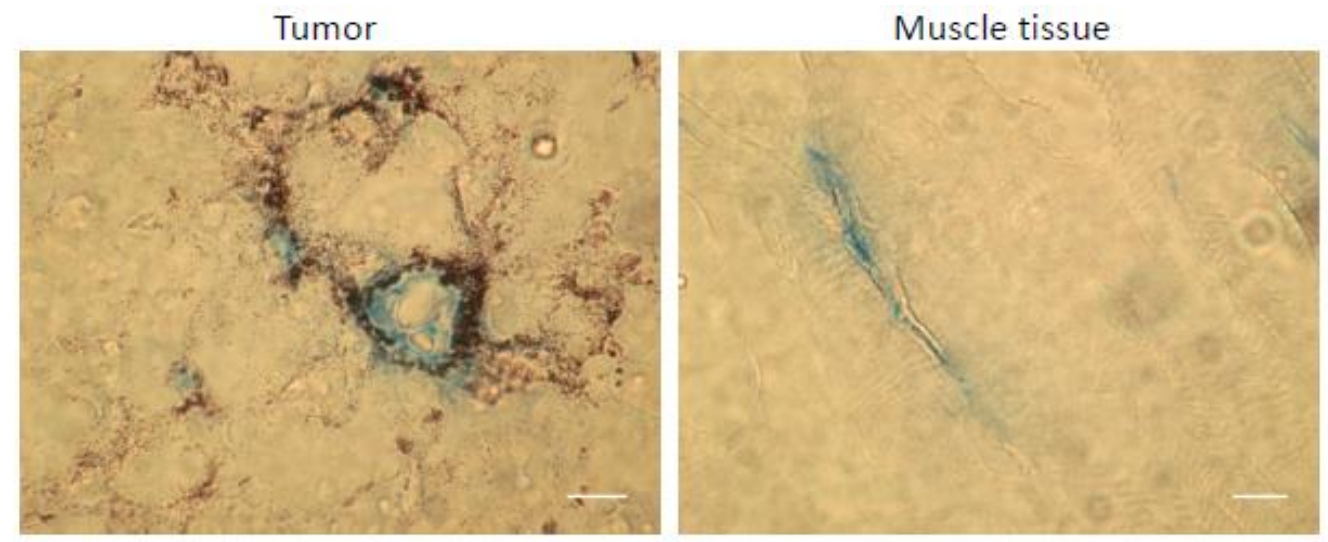

Figure 3-8: Immunohistochemical staining for CD31 (blue) and RFP (brownish red) in transfected tissue. Scale bar represents $10 \mu \mathrm{m}$.

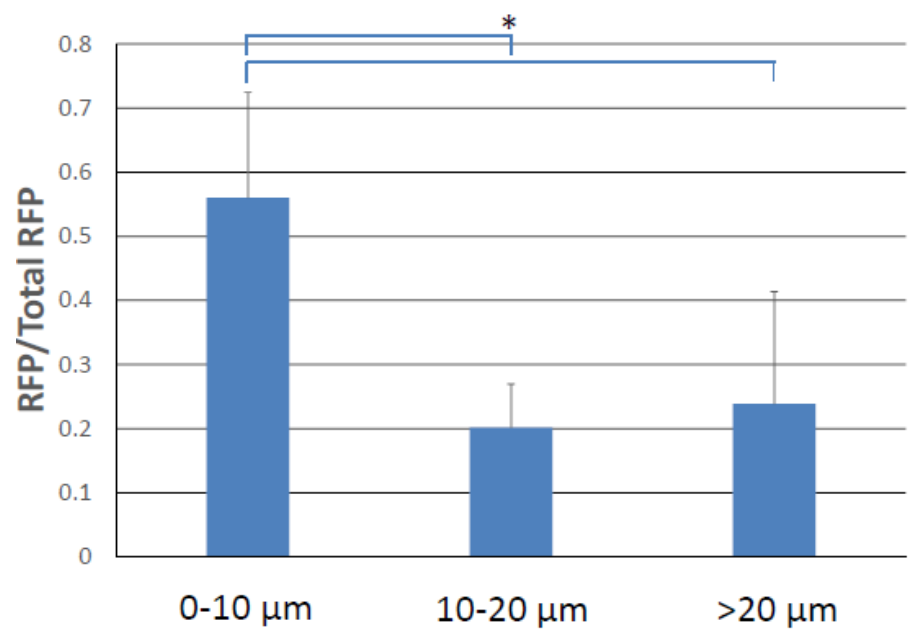

Figure 3-9: Percentage of RFP $^{+}$area within different distances of tumor blood vessels. $n=3$; 2tailed $T$ test with unequal variance; ${ }^{*} p<0.01$

\section{Discussion}

In this chapter, we demonstrated VEGFR2-targeted transfection of a reporter plasmid using ultrasound-mediated destruction of microbubbles. During in vitro transfection (Figure 3-5), the transfection efficiency was increasing with intensities in the range of $0-0.65 \mathrm{~W} / \mathrm{cm}^{2}$ but did not increase with increasing intensity from $0.65-5.20 \mathrm{~W} / \mathrm{cm}^{2}$. This trend was also seen in a different transducer 


\section{Chapter 3: Targeted transfection of B16-F1 melanoma tumors using a RFP reporter gene}

(Tlaxca et al. 2010) albeit at a higher intensity of $2 \mathrm{~W} / \mathrm{cm}^{2}$ and above. A possible explanation for this difference is that the duty cycle for our transducer was at $100 \%$ as opposed to $25 \%$.

For in vivo transfection, the DNA payload of cationic microbubbles was measured to be $1.29 \pm$ $0.23 \mu \mathrm{g}$ of DNA / $10^{8} \mathrm{MB}$. Previous studies have described microbubble payloads of $1-8 \mu \mathrm{g}$ of DNA / $10^{8}$ MB (Phillips et al. 2010b,Christiansen et al. 2003, Tlaxca et al. 2010,Wang et al. 2012). Variations in cationic microbubble payload can result from differences in the size of the plasmid or the amount of positively charged lipid incorporated into the bubble shell, which can range from $1-10 \%$, depending on the microbubble design.

The appearance of a non-perfused region specific to the tumor after two rounds of transfection using an intensity of $3.79 \mathrm{~W} / \mathrm{cm}^{2}$ was unexpected since an intensity of $5 \mathrm{~W} / \mathrm{cm}^{2}$ has been used to successfully transfect mesentery tissue without adverse effects (Tlaxca et al. 2013). An attempt to reproduce the non-perfusion effect in B16 melanoma tumors with untargeted microbubbles were unsuccessful even with up to four rounds of bubble destruction, future work to identify the source of targeted tumor necrosis would include trying VEGFR2-targeted bubbles and VEGFR2-targeted bubbles with PEI. Positively charged polymers such as PEI are known to have cell toxicity effects in vitro and in vivo. It is also possible the reporter gene once transfected into the vessel wall might result in local cell death. However, the reporter gene used, luciferase, is not known to be broadly toxic to cells transfected in vivo. It is also possible that coagulation could be triggered by the deposition of highly charged polymers such as $\mathrm{PEI}$, which can activate the contact pathway of fibrin generation. In addition, information regarding the duration of the blood vessel occlusion could be obtained through bubble perfusion imaging hours later and would be useful in determining whether this could potentially be applied to tumor therapy. 


\section{Chapter 3: Targeted transfection of B16-F1 melanoma tumors using a RFP reporter gene}

In light of the possibility that either the carrier polymer, the reporter gene, or the power of the transducer might be limiting gene expression due to excessive localized necrosis, I changed the reporter gene to RFP, abandoned the use of PEI to boost plasmid compaction and payload, used a lower setting of transducer power, and limited the number of in situ transfections to one.

Following these procedural modifications, it was observed that tumor-specific transfection of RFP reporter plasmid could be detected using immunohistochemistry methods. Since a majority of the RFP signal was within $10 \mu \mathrm{m}$ of a blood vessel, we can infer that either mostly endothelial cells or tumor cells adjacent to endothelial cells were being transfected. Sonoporation in other tissues have demonstrated gene delivery to endothelial cells (Phillips et al. 2010b,Christiansen et al. 2003,Tlaxca et al. 2013) and possibly adjacent stroma cells. Microbubble facilitated transfection of non-endothelial cells has been previously reported, but these approaches did not exploit endothelial targeted microbubbles (Carson et al. 2012,Christiansen et al. 2003, Chen et al. 2006,Shohet et al. 2000).

The limitation for using immunohistochemistry to look for co-localization is that steric hindrance from the colored product of the enzyme-substrate reaction of the first antibody can mask binding sites for the second antibody. An alternative is to stain for the different antigens on sequential tissue sections, but locating the same FOV on sequential sections can be challenging and requires specialized imaging tools and software to ensure correct registration of the images. In comparison, immunofluorescence is an easier technique for determining co-localization. Future work could include delivery of a plasmid encoding a membrane-bound form of RFP or otherwise unique membrane anchored marker, which would allow for immunofluorescence staining of CD31 on unfixed frozen tissue sections without having to be concerned about loss of RFP during processing. RFP is a protein that has minimal interactions with the cell's cytoplasmic contents and thus is easily lost from thin sectioned tissues during labeling 
procedures. Determining the cell types that are being transfected is important since that could limit the type of therapeutic plasmid that can be delivered.

\section{References}

Bekeredjian R, Chen S, Frenkel PA, Grayburn PA, Shohet RV. Ultrasound-targeted microbubble destruction can repeatedly direct highly specific plasmid expression to the heart. Circulation 2003;108:1022-6.

Borden MA, Caskey CF, Little E, Gillies RJ, Ferrara KW. DNA and polylysine adsorption and multilayer construction onto cationic lipid-coated microbubbles. Langmuir 2007;23:9401-8.

Burke CW, Suk JS, Kim AJ, Hsiang YH, Klibanov AL, Hanes J, Price RJ. Markedly enhanced skeletal muscle transfection achieved by the ultrasound-targeted delivery of non-viral gene nanocarriers with microbubbles. J Control Release 2012;162:414-21.

Carson AR, McTiernan CF, Lavery L, Grata M, Leng X, Wang J, Chen X, Villanueva FS. Ultrasound-targeted microbubble destruction to deliver siRNA cancer therapy. Cancer Res 2012;72:6191-9.

Chen S, Ding JH, Bekeredjian R, Yang BZ, Shohet RV, Johnston SA, Hohmeier HE, Newgard CB, Grayburn PA. Efficient gene delivery to pancreatic islets with ultrasonic microbubble destruction technology. Proc Natl Acad Sci U S A 2006;103:8469-74.

Chen S, Shohet RV, Bekeredjian R, Frenkel P, Grayburn PA. Optimization of ultrasound parameters for cardiac gene delivery of adenoviral or plasmid deoxyribonucleic acid by ultrasound-targeted microbubble destruction. J Am Coll Cardiol 2003;42:301-8.

Chen ZY, Liang K, Qiu RX. Targeted gene delivery in tumor xenografts by the combination of ultrasoundtargeted microbubble destruction and polyethylenimine to inhibit survivin gene expression and induce apoptosis. J Exp Clin Cancer Res 2010;29:152,9966-29-152.

Christiansen JP, French BA, Klibanov AL, Kaul S, Lindner JR. Targeted tissue transfection with ultrasound destruction of plasmid-bearing cationic microbubbles. Ultrasound Med Biol 2003;29:1759-67.

Li YS, Davidson E, Reid CN, McHale AP. Optimising ultrasound-mediated gene transfer (sonoporation) in vitro and prolonged expression of a transgene in vivo: potential applications for gene therapy of cancer. Cancer Lett 2009;273:62-9.

Panje CM, Wang DS, Pysz MA, Paulmurugan R, Ren Y, Tranquart F, Tian L, Willmann JK. Ultrasoundmediated gene delivery with cationic versus neutral microbubbles: effect of DNA and microbubble dose on in vivo transfection efficiency. Theranostics 2012;2:1078-91.

Phillips LC, Klibanov AL, Bowles DK, Ragosta M, Hossack JA, Wamhoff BR. Focused in vivo delivery of plasmid DNA to the porcine vascular wall via intravascular ultrasound destruction of microbubbles. J Vasc Res 2010a;47:270-4. 
Phillips LC, Klibanov AL, Wamhoff BR, Hossack JA. Targeted gene transfection from microbubbles into vascular smooth muscle cells using focused, ultrasound-mediated delivery. Ultrasound Med Biol 2010b;36:1470-80.

Shohet RV, Chen S, Zhou YT, Wang Z, Meidell RS, Unger RH, Grayburn PA. Echocardiographic destruction of albumin microbubbles directs gene delivery to the myocardium. Circulation 2000;101:2554-6.

Sirsi SR, Hernandez SL, Zielinski L, Blomback H, Koubaa A, Synder M, Homma S, Kandel JJ, Yamashiro DJ, Borden MA. Polyplex-microbubble hybrids for ultrasound-guided plasmid DNA delivery to solid tumors. J Control Release 2012;157:224-34.

Suzuki R, Takizawa T, Negishi Y, Utoguchi N, Sawamura K, Tanaka K, Namai E, Oda Y, Matsumura Y, Maruyama K. Tumor specific ultrasound enhanced gene transfer in vivo with novel liposomal bubbles. J Control Release 2008;125:137-44.

Tlaxca JL, Anderson CR, Klibanov AL, Lowrey B, Hossack JA, Alexander JS, Lawrence MB, Rychak JJ. Analysis of in vitro transfection by sonoporation using cationic and neutral microbubbles. Ultrasound Med Biol 2010;36:1907-18.

Tlaxca JL, Rychak JJ, Ernst PB, Konkalmatt PR, Shevchenko TI, Pizzaro TT, Rivera-Nieves J, Klibanov AL, Lawrence MB. Ultrasound-based molecular imaging and specific gene delivery to mesenteric vasculature by endothelial adhesion molecule targeted microbubbles in a mouse model of Crohn's disease. J Control Release 2013;165:216-25.

Wang DS, Panje C, Pysz MA, Paulmurugan R, Rosenberg J, Gambhir SS, Schneider M, Willmann JK. Cationic versus neutral microbubbles for ultrasound-mediated gene delivery in cancer. Radiology 2012;264:721-32.

Xie A, Belcik T, Qi Y, Morgan TK, Champaneri SA, Taylor S, Davidson BP, Zhao Y, Klibanov AL, Kuliszewski MA, Leong-Poi H, Ammi A, Lindner JR. Ultrasound-mediated vascular gene transfection by cavitation of endothelial-targeted cationic microbubbles. JACC Cardiovasc Imaging 2012;5:1253-62. 


\section{Chapter 4: Future work}

In Chapter 2, it was demonstrated tumor-specific targeting with VEGFR2-targeted microbubbles but not with VCAM-1 targeted bubbles. VCAM-1 targeted bubbles bound to tumor, adjacent non-tumor tissue, and contralateral leg endothelium at high levels compared to control bubbles. In future work, it would be important to image VCAM-1-targeted bubble binding to mice pre- and post-tumor induction to determine whether systemic VCAM-1 expression on endothelial cells is associated with tumor presence. Expression of VCAM-1 on non-tumor endothelial cells could be a barrier to tumor immunotherapy if leukocytes are extravasating into non-tumor tissue instead of primarily into the tumor microenvironment. Extension, or screening of other angiogenic markers or even markers associated with melanoma endothelium for microbubble detection would be important to both map the tumor vasculature and to optimize tumor detection.

In Chapter 3, ultrasound-mediated destruction of VEGFR2-targeted microbubbles was used to deliver RFP plasmid to B16-F1 melanoma tumors. Immunohistochemical staining showed gene transfer specific to tumor tissue and not to adjacent non-tumor tissue. Future work to further assess tumortargeting specificity will include immunohistochemical staining for RFP expression in organs such as the liver and kidney where non-specific gene transfer has a high likelihood of occurring. It is anticipated that the dual targeting approach developed in this study will likely result in very low levels of off-target plasmid expression. Additionally, transfection will be repeated using a reporter plasmid encoding luciferase instead of RFP. In vivo bioluminescence imaging is sensitive and allows quick assessment of gene expression in the entire mouse compared to immunohistochemical staining of tissue sections. Whole body chemiluminesence can further establish the level of tumor specificity of gene expression. Further work to improve gene delivery to melanoma tumors will include utilizing cationic polymers such as PEI to increase the DNA binding capacity and transfection efficiency of microbubbles. The evidence of localized tumor toxicity is by itself a potentially important observation that suggests an alternative approach to melanoma therapy-that of targeted necrosis. More work will be required to establish 


\section{Chapter 4: Future work}

whether there is clot formation that leads to tumor necrosis or whether the effect is related to sonoporation triggered apoptosis of the vascular endothelial cells.

Lastly, to improve the biocompatibility of the bubble gene delivery platform, covalent attachment of targeting ligand to the bubbles can be used in place of biotin and streptavidin. The appearance of a non-perfused region specific to the tumor after two rounds of transfection using an intensity of $3.79 \mathrm{~W} / \mathrm{cm}^{2}$ was an unexpected result that could be further explored as an alternative therapeutic strategy for melanoma tumors. 